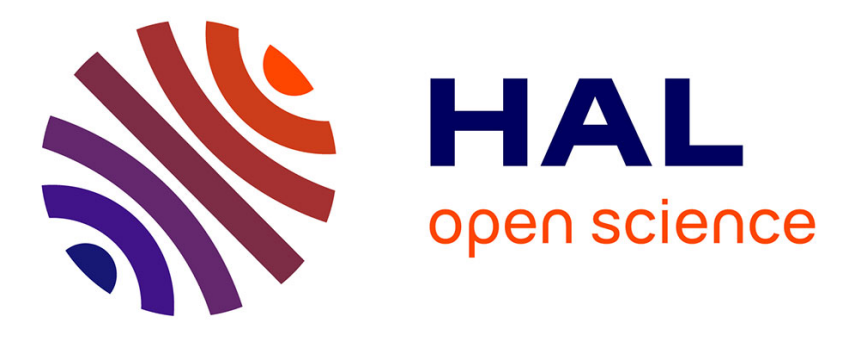

\title{
Photophysical Investigation of Iron(II) Complexes Bearing Bidentate Annulated Isomeric Pyridine-NHC Ligands
}

Kevin Magra, Mohamed Darari, Edoardo Domenichini, Antonio

Francés-Monerris, Cristina Cebrian, Marc Beley, Mariachiara Pastore, Antonio Monari, Xavier Assfeld, Stefan Haacke, et al.

\section{To cite this version:}

Kevin Magra, Mohamed Darari, Edoardo Domenichini, Antonio Francés-Monerris, Cristina Cebrian, et al.. Photophysical Investigation of Iron(II) Complexes Bearing Bidentate Annulated Isomeric Pyridine-NHC Ligands. Journal of Physical Chemistry C, 2020, 124 (34), pp.18379-18389. 10.1021/acs.jpcc.0c03638 . hal-02918450

\section{HAL Id: hal-02918450 \\ https://hal.science/hal-02918450}

Submitted on 23 Sep 2020

HAL is a multi-disciplinary open access archive for the deposit and dissemination of scientific research documents, whether they are published or not. The documents may come from teaching and research institutions in France or abroad, or from public or private research centers.
L'archive ouverte pluridisciplinaire HAL, est destinée au dépôt et à la diffusion de documents scientifiques de niveau recherche, publiés ou non, émanant des établissements d'enseignement et de recherche français ou étrangers, des laboratoires publics ou privés. 


\section{Photophysical Investigation of Iron(II) Complexes}

\section{bearing Bidentate Annulated Isomeric Pyridine-}

\section{NHC Ligands}

Kevin Magra, ${ }^{a}$ Mohamed Darari, ${ }^{b}$ Edoardo Domenichini, ${ }^{c}$ Antonio Francés-Monerris,,${ }^{, e}$

Cristina Cebrián, ${ }^{a}$ Marc Beley, ${ }^{b}$ Mariachiara Pastore, ${ }^{d}$ Antonio Monari, ${ }^{d}$ Xavier Assfeld, ${ }^{d}$ Stefan Haacke $^{c}$ and Philippe C. Gros $*, b$

${ }^{a}$ Université de Lorraine, CNRS, L2CM, F-57000 Metz, France

${ }^{\mathrm{b}}$ Université de Lorraine, CNRS, L2CM, F-54000 Nancy, France

${ }^{\mathrm{c}}$ Université de Strasbourg, CNRS, IPCMS, F-67000 Strasbourg, France

${ }^{\mathrm{d}}$ Université de Lorraine, CNRS, LPCT, F-54000 Nancy, France

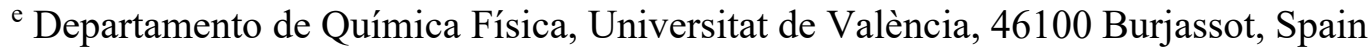

\section{AUTHOR INFORMATION}

\section{Corresponding Author}

*Philippe C. Gros: philippe.gros@univ-lorraine.fr

KEYWORDS. iron complexes, fused NHC, photophysics, TD-DFT, Minimum Energy Path, decay process 


\begin{abstract}
The possibility of achieving luminescent and photophysically active metal-organic compounds relies on the stabilization of charge transfer states and kinetically and thermodynamically blocking non-radiative dissipative channels. In this contribution we explore the behavior of bidentate iron complexes bearing $\mathrm{N}$-heterocyclic carbene ligands with extended conjugation systems by a multidisciplinary approach combining chemical synthesis, ultrafast time-resolved spectroscopy, and molecular modeling. Lifetimes of the metal-to-ligand charge transfer and metal-centered states reaching up to $\approx 20$ picoseconds are evidenced, while complex decay mechanisms are pointed out, together with a possible influence of the facial and meridional isomerism. The structural degrees of freedom driving the non-radiative processes are highlighted and their rigidification is suggested as an effective way to further increase the lifetimes.
\end{abstract}

\title{
INTRODUCTION
}

$\mathrm{N}$-heterocyclic carbenes (NHCs) are highly popular ligands in catalysis due to their strong $\sigma$ donating properties and low dissociation rates. ${ }^{1-6}$ Recently, these ligands have allowed to strongly improve the photophysical properties of iron(II) complexes making them appealing for optically active devices or as cheaper and non-toxic alternative to ruthenium-based sensitizers in solar energy applications. ${ }^{7-14}$ However, controlling the photophysics of first-row transition metal complexes is challenging compared with heavier elements. For example, while ruthenium(II) polypyridyl complexes exhibit long-lived metal-to-ligand (MLCT) triplet states, ${ }^{15}$ ultrafast relaxation to metal centred (MC) states and subsequent ground-state recovery are observed for iron 
analogues. ${ }^{16-19}$ However, the combination of the $\pi$-deficiency of pyridine and the $\sigma$-donation of NHC in pyridyl-NHC iron(II) complexes is effective in altering the energy order of the excited state manifold. Thus, important breakthroughs in increasing the MLCT lifetime have been achieved, ${ }^{8,20-25}$ from tens of picoseconds for azinyl-NHC iron(II) complexes with tridentate $\mathrm{C}^{\wedge} \mathrm{N}^{\wedge} \mathrm{C}^{26-30}$ and bidentate $\mathrm{C}^{\wedge} \mathrm{N}$ ligands ${ }^{31,32}$ to the nanosecond domain for scorpionate-like $\mathrm{C}^{\wedge} \mathrm{C}^{\wedge} \mathrm{C}$ ligands, this latter even showing luminescent properties. $^{33}$

We have recently shown that for $\mathrm{C}^{\wedge} \mathrm{N}^{\wedge} \mathrm{C}$ ligands, framing the carbene moiety with extended $\pi$ conjugated systems notably stabilizes the MLCT excited state, and prevents spin crossover into the $\mathrm{MC}$ quintuplet ${ }^{5} \mathrm{MC}$, by enhancing the $\pi$-back donation from the iron center to the ligand, hence leading to prolonged excited state lifetimes..$^{28,30}$ Bidentate $\mathrm{C}^{\wedge} \mathrm{N}$ ligands also brought an improvement by reducing the angular strain around the metal center upon coordination approaching a more ideal octahedral geometry and with a concomitant increase of the ligand field splitting. ${ }^{32}$ Thus, these findings prompted us to investigate the design of $\pi$-conjugated $\mathrm{C}^{\wedge} \mathrm{N}$ ligands with the aim to exploit the combination of both geometric and electronic beneficial effects.

Nevertheless, bidentate complexes come in a mixture of fac and mer isomers, which may complicate the analysis of their spectroscopic and electrochemical properties. The effect of such isomerism has been studied in recent publications dedicated to the excited state dynamics of the parent $\mathbf{C 0}$ complex (Figure 1) featuring less than $10 \%$ fac configuration, ${ }^{31,34}$ and a $100 \%$ fac form of $\mathbf{C O}$ obtained by a tripodal interconnection of the three ligands. ${ }^{31,32}$ Irrespective of the ligand arrangement, two excited states $T_{1}$ and $T_{2}$ are populated after intersystem crossing from the optically active ${ }^{1}$ MLCT manifold. The computational analysis revealed that their character is still MLCT at the beginning of the excited-state relaxation pathway. However, the triplet manifold evolves elongating a Fe-N bond gradually and adiabatically increasing the MC character of the 
states, reaching spin-crossover regions and farther singlet-triplet crossings that mediate the ground state recovery. In addition, femtosecond spectroscopy showed that the two $\mathrm{T}_{1}$ and $\mathrm{T}_{2}$ states differ in their recovery times, which are in the $2-3$ and $\approx 15$ ps range, respectively, regardless of the isomer considered. The isomerism solely modulates the relative population of these two excitedstate deactivation channels, the mer form exhibiting a globally faster decay.

Herein we report the synthesis and the characterization of the mostly mer iron(II) complexes C1, C2 and C3, with pyridyl-NHC bidentate ligands containing benzimidazole (BIm) and imidazo[1,5a]pyridine-based (ImP) conjugated carbene moieties (Figure 1). The photophysical properties of the complexes have been investigated by ultrafast time-resolved spectroscopy and TD-DFT calculations. Unlike previous tridentate complexes studied by our group, ${ }^{28,30}$ and despite significant modifications of the ground state absorption spectra, it turns out that the substitutions of imidazole by BIm or ImP do not have a significant effect on the excited state electronic structure and relaxation dynamics. The strategy based on altering the relative positions of the $\mathrm{MC}$ and MLCT energy levels by acting on the ligand field splitting at various levels has been instrumental in allowing the breakthrough of avoiding the spin-crossover transition and leading to the increase of the MLCT lifetimes from the sub-picosecond regime to tens of picoseconds. ${ }^{8,21,28-30,33}$ However, it appears that, for complexes with 3 or 4 carbene bonds, this strategy is reaching its limit, as also shown by the present results. To further increase the lifetimes, a kinetic blocking of the geometrical degrees of freedom leading to the deactivation should be effective, as confirmed by the general better performance of the more rigid tridentate complexes. Indeed, iron compounds showing lifetimes at the nanosecond scale present multiple $\pi$-stacking interactions participating to the rigidification of the coordination sphere. ${ }^{22}$ The results presented in the present article allow for a rationalization of the different factors leading to the excited states deactivation and can hence 
provide supplementary evidences for a likely needed change in the paradigm guiding the rational and efficient design of photoactive iron compounds.

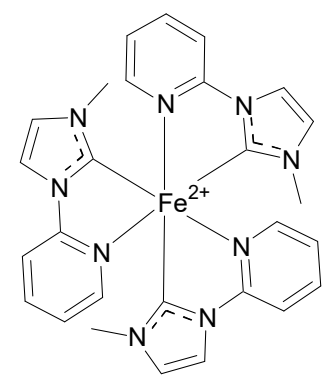

Co

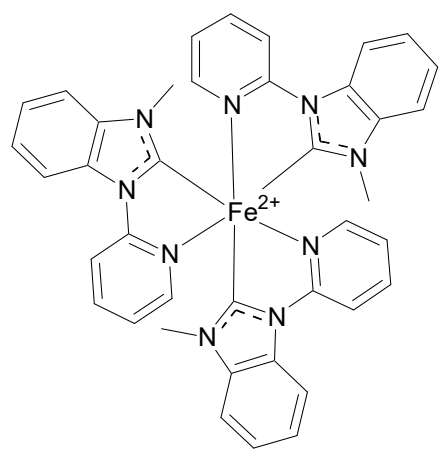

C1

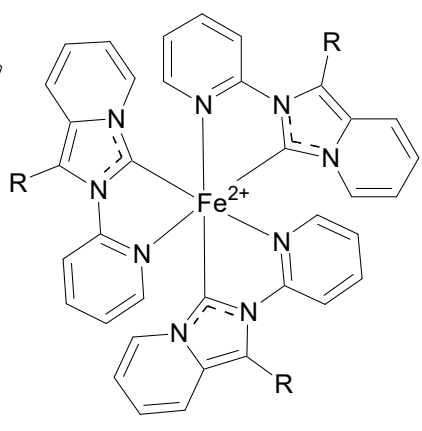

C2, $\mathrm{R}=\mathrm{H}$ $\mathrm{C} 3, \mathrm{R}=\mathrm{Me}$

Figure1. Complexes studied in this work. Counter ion is $\mathrm{PF}_{6}{ }^{-}$in every case

\section{MATERIALS AND METHODS}

Solvents and commercially available reagents were used as received. Monomode microwave irradiations were conducted using an Anton Paar Monowave 450 equipped with a noninvasive IR sensor. Thin layer chromatography (TLC) was performed by using silica gel 60 F-254 (Merck) plates and visualized under UV light. Chromatographic purification was performed by using silica gel $60(0.063-0.2 \mathrm{~mm} / 70-230 \mathrm{mesh}) .{ }^{1} \mathrm{H}(400 \mathrm{MHz})$ and ${ }^{13} \mathrm{C}$ NMR $(100 \mathrm{MHz})$ spectra were taken on an AC Bruker spectrometer at ambient temperature. The chemical shifts $(\delta)$, were calibrated by using either tetramethylsilane (TMS) or signals from the residual protons of the deuterated solvents and are reported in parts per million (ppm) from low to high field. High-resolution mass spectrometry (HRMS) data was obtained by using Bruker micrOTOF-Q spectrometer. UV-vis spectra were recorded in a $1 \mathrm{~cm}$ path length quartz cell on a Varian Cary 50 spectrophotometer. Cyclic voltammetry was performed on a Radiometer PST006 potentiostat using a conventional 
three-electrode cell. The saturated calomel electrode (SCE) was separated from the test compartment using a bridge tube. The solutions of studied complexes $(0.2 \mathrm{mM})$ were purged with argon before each measurement. The test solution was acetonitrile containing $0.1 \mathrm{M} \mathrm{Bu}_{4} \mathrm{NPF}_{6}$ as supporting electrolyte. The working electrode was a vitreous carbon $\operatorname{rod}(1 \mathrm{~cm} 2)$ wire and the counter-electrode was a $1 \mathrm{~cm}^{2} \mathrm{Pt}$ disc. After the measurement, ferrocene was added as the internal reference for calibration. All potentials were quoted versus SCE. In these conditions the redox potential of the couple $\mathrm{Fc}+/ \mathrm{Fc}$ was found at $0.39 \mathrm{~V}$. In all the experiments the scan rate was $100 \mathrm{mV} / \mathrm{s}$.

\section{Synthesis of ligands}

L1. ${ }^{35}$ 2-Pyridylbenzimidazole (400 mg, $2.05 \mathrm{mmol}$ ) and iodomethane (2.20 mL, $\left.20.51 \mathrm{mmol}\right)$ were heated for $1 \mathrm{~h}$ in $4 \mathrm{~mL}$ of acetonitrile at $100^{\circ} \mathrm{C}$ under microwave irradiation $(60 \mathrm{~W})$. After evaporation of solvent, the resulting mixture was dissolved in water. Then, the metathesis was made by addition of saturated solution of $\mathrm{KPF}_{6}$. The solid was filtered, washed twice with $\mathrm{Et}_{2} \mathrm{O}$, and dried under vacuum to give a yellow powder (469 mg, 66\%). ${ }^{1} \mathrm{H}$ NMR (400 MHz, DMSO-d6) $: \delta=10.40(\mathrm{~s}, 1 \mathrm{H}), 8.77(\mathrm{ddd}, J=0.80,1.80,4.80 \mathrm{~Hz}, 1 \mathrm{H}), 8.48-8.43(\mathrm{~m}, 1 \mathrm{H}), 8.27(\mathrm{dt}, J=8.10$ $2.00 \mathrm{~Hz}, 1 \mathrm{H}), 8.15-8.10(\mathrm{~m}, 1 \mathrm{H}), 8.01(\mathrm{td}, J=8.300,1.04 \mathrm{~Hz}, 1 \mathrm{H}), 7.82-7.75(\mathrm{~m}, 2 \mathrm{H}), 7.71$ $(\mathrm{ddd}, J=7.48,4.78,1.04 \mathrm{~Hz}, 1 \mathrm{H}), 4.18(\mathrm{~s}, 3 \mathrm{H}) \mathrm{ppm} .{ }^{13} \mathrm{C} \mathrm{NMR}\left(100 \mathrm{MHz}, \mathrm{ACN}-\mathrm{d}_{3}\right): \delta=149.5$, $147.2,142.5,140.6,132.2,129.3,127.3,127.1,125.0,116.8,115.6,113.8,33.7 \mathrm{ppm}$.

L2. ${ }^{36}$ 2-aminopyridine (400 mg, $4.25 \mathrm{mmol}$ and paraformaldehyde (192 mg, $6.38 \mathrm{mmol}$ ) were heated for $30 \mathrm{~min}$ in $4 \mathrm{~mL}$ of acetonitrile at $80^{\circ} \mathrm{C}$ under microwave irradiation $(60 \mathrm{~W})$. Then picolinaldehyde $(0.41 \mathrm{~mL}, 4.25 \mathrm{mmol})$ and a solution of $\mathrm{HCl} 3 \mathrm{M}$ in acetonitrile $(2 \mathrm{~mL})$ were added 
and heated for $1 \mathrm{~h}$ at $100^{\circ} \mathrm{C}$ under microwave irradiation $(60 \mathrm{~W})$. After evaporation of solvent, the resulting mixture was dissolved in water. Then, the metathesis was made by addition of saturated solution of $\mathrm{KPF}_{6}$. The solid was filtered, washed twice with $\mathrm{Et}_{2} \mathrm{O}$, and dried under vacuum to give yellow powder (1.43 g, 98\%). ${ }^{1} \mathrm{H}$ NMR (400 MHz, DMSO-d $): \delta=10.57$ (s, $\left.1 \mathrm{H}\right), 8.99(\mathrm{~s}, 1 \mathrm{H})$, $8.74(\mathrm{ddd}, J=4.80,1.80,0.80 \mathrm{~Hz}, 1 \mathrm{H}), 8.60(\mathrm{dd}, J=7.18,0.88 \mathrm{~Hz}, 1 \mathrm{H}), 8.29(\mathrm{td}, J=7.50,1.80$ $\mathrm{Hz}, 1 \mathrm{H}), 8.21(\mathrm{~d}, J=8.10 \mathrm{~Hz}, 1 \mathrm{H}), 7.93(\mathrm{~d}, J=9.32 \mathrm{~Hz}, 1 \mathrm{H}), 7.73(\mathrm{ddd}, J=7.43,4.78,0.88 \mathrm{~Hz}$, $1 \mathrm{H}), 7.34(\mathrm{ddd}, J=9.30,2.30,0.80 \mathrm{~Hz}, 1 \mathrm{H}), 7.28(\mathrm{td}, J=6.80,1.30 \mathrm{~Hz}, 1 \mathrm{H}) \mathrm{ppm}$.

L3. ${ }^{36}$ 2-aminopyridine (400 mg, $4.25 \mathrm{mmol}$ and paraformaldehyde (192 mg, $6.38 \mathrm{mmol}$ ) were heated for $30 \mathrm{~min}$ in $4 \mathrm{~mL}$ of acetonitrile at $80^{\circ} \mathrm{C}$ under microwave irradiation $(60 \mathrm{~W})$. Then 2acetylpyridine $(0.48 \mathrm{~mL}, 4.25 \mathrm{mmol})$ and a solution of $\mathrm{HCl} 3 \mathrm{M}$ in acetonitrile $(2 \mathrm{~mL})$ were added and heated for $1 \mathrm{~h}$ at $100^{\circ} \mathrm{C}$ under microwave irradiation $(60 \mathrm{~W})$. After evaporation of solvent, the resulting mixture was dissolved in water. Then, the metathesis was made by addition of saturated solution of $\mathrm{KPF}_{6}$. The solid was filtered, washed twice with $\mathrm{Et}_{2} \mathrm{O}$, and dried under vacuum to give yellow powder (1 g, 67\%). ${ }^{1} \mathrm{H}$ NMR (400 MHz, DMSO-d $): \delta=10.16(\mathrm{~s}, 1 \mathrm{H}), 8.90-8.74(\mathrm{~m}, 1 \mathrm{H})$, $8.60-8.45(\mathrm{~m}, 1 \mathrm{H}), 8.29(\mathrm{dt}, J=7.81,1.76 \mathrm{~Hz}, 1 \mathrm{H}), 8.03(\mathrm{~d}, J=8.56 \mathrm{~Hz}, 1 \mathrm{H}), 7.99-7.93(\mathrm{~m}, 1 \mathrm{H})$, 7.80 (ddd, $J=7.55,4.78,1.01 \mathrm{~Hz}, 1 \mathrm{H}), 7.32-7.19$ (m, 2H), $2.71(\mathrm{~s}, 3 \mathrm{H}) \mathrm{ppm}$.

\section{Synthesis of complexes}

C1. Using Schlenk techniques, ligand $\mathbf{L 1}(200 \mathrm{mg}, 0.56 \mathrm{mmol})$ and $\mathrm{FeCl}_{2}(24 \mathrm{mg}, 0.19 \mathrm{mmol})$ were dissolved in $2 \mathrm{~mL}$ of DMF. Potassium tert-butoxide (70 $\mathrm{mg}, 0.62 \mathrm{mmol}$ ) was then added. The dark red solution was stirred at room temperature (rt) for 10 min. After evaporation of DMF, the residue was purified by column chromatography using water/acetone/ $\mathrm{KNO}_{3}(10 / 2 / 1)$ as eluent. The red fractions were evaporated, and a saturated solution of $\mathrm{KPF}_{6}$ was added. The obtained solid 
was filtered, washed twice with $\mathrm{Et}_{2} \mathrm{O}$, and dried under vacuum to give a non-separable mixture of both $f a c$ - and mer-C1 in 1:6 ratio (60 mg, 33\%) as an orange solid. ${ }^{1} \mathrm{H}$ NMR (400 MHz, ACN-d 3 ) $: \delta=8.51(\mathrm{~d}, J=8.31 \mathrm{~Hz}, 1 \mathrm{H}), 8.44(\mathrm{~d}, J=8.30 \mathrm{~Hz}, 1 \mathrm{H}), 8.32(\mathrm{~d}, J=7.81 \mathrm{~Hz}, 1 \mathrm{H}), 8.11-8.28$ (m, $7 \mathrm{H}), 8.08(\mathrm{~d}, J=4.78 \mathrm{~Hz}, 1 \mathrm{H}), 7.91-8.00(\mathrm{~m}, 2 \mathrm{H}), 7.43-7.68(\mathrm{~m}, 13 \mathrm{H}), 7.21-7.29(\mathrm{~m}, 2$ H), $7.10(\mathrm{~d}, J=5.30 \mathrm{~Hz}, 1 \mathrm{H}), 6.88-7.00(\mathrm{~m}, 3 \mathrm{H}), 3.41(\mathrm{~s}, 3 \mathrm{H}), 3.19(\mathrm{~s}, 9 \mathrm{H}), 2.94(\mathrm{~s}, 3 \mathrm{H}), 2.89$ (s, $3 \mathrm{H})$ ppm. ${ }^{13} \mathrm{C}$ NMR $\left(100 \mathrm{MHz}, \mathrm{ACN}-\mathrm{d}_{3}\right): \delta=218.2,218.2,215.7,215.7,157.4,156.9,156.3$, $155.9,155.8,155.0,152.4,150.8,142.2,141.5,141.1,140.0,140.0,139.7,139.6,139.2,132.9$, $132.5,132.5,132.4,125.9,125.9,125.7,125.7,125.6,125.5,125.3,124.9,124.6,124.0,123.4$, $122.8,114.7,114.4,113.9,133.5,113.2,113.1,112.5,122.4,112.3,111.9,111.7,111.2,34.3$, 34.0, 32.5, 32.4 ppm. HRMS calcd for $\mathrm{C}_{39} \mathrm{H}_{33} \mathrm{FeN}_{9} \mathrm{P}_{2} \mathrm{~F}_{12} \mathrm{~m} / z: 341.6099\left[\mathrm{M}-2 \mathrm{PF}_{6}\right]^{2+}$. Found 341.6104 .

C2. The procedure was the same as for $\mathbf{C 1}$ using $\mathbf{~} 2$ (600 $\mathrm{mg}, 1.76 \mathrm{mmol}), \mathrm{FeCl}_{2}$ (74 $\mathrm{mg}, 0.58$ mmol) and potassium tert-butoxide $(217 \mathrm{mg}, 1.94 \mathrm{mmol})$ in $6 \mathrm{~mL}$ of DMF. The column chromatography was performed with water/acetone/ $\mathrm{KNO}_{3}(9 / 2 / 1)$ as eluent. A non-separable mixture of both $f a c$ - and $m e r-\mathbf{C} 2$ in $1: 3$ ratio $(220 \mathrm{mg}, 38 \%)$ was obtained as an orange solid. ${ }^{1} \mathrm{H}$ NMR $\left(400 \mathrm{MHz}, \mathrm{ACN}-\mathrm{d}_{3}\right): \delta=8.65(\mathrm{~s}, 1 \mathrm{H}), 8.55(\mathrm{~s}, 1 \mathrm{H}), 8.52(\mathrm{~s}, 1 \mathrm{H}), 8.46(\mathrm{~s}, 1 \mathrm{H}), 8.12-8.31$ (m, $5 \mathrm{H}), 7.94-8.04(\mathrm{~m}, 4 \mathrm{H}), 7.82(\mathrm{dd}, J=5.80,0.80 \mathrm{~Hz}, 1 \mathrm{H}), 7.57(\mathrm{td}, J=9.30,1.30 \mathrm{~Hz}, 2 \mathrm{H})$, $7.47(\mathrm{~d}, J=9.30 \mathrm{~Hz}, 2 \mathrm{H}), 7.29-7.37$ (m, $3 \mathrm{H}), 7.14(\mathrm{~d}, 1 \mathrm{H}), 6.99-7.10$ (m, $3 \mathrm{H}), 6.78-6.94$ (m, 4 H), $6.32(\mathrm{~m}, 4 \mathrm{H}), 5.99(\mathrm{dd}, J=7.30,1.00 \mathrm{~Hz}, 1 \mathrm{H}), 5.70(\mathrm{dd}, J=7.50,1.00 \mathrm{~Hz}, 1 \mathrm{H}), 5.62(\mathrm{dd}, J$ $=7.30,1.00 \mathrm{~Hz}, 1 \mathrm{H}) \mathrm{ppm} .{ }^{13} \mathrm{C} \mathrm{NMR}\left(100 \mathrm{MHz}, \mathrm{ACN}-\mathrm{d}_{3}\right): \delta=200.2,198.4,195.7,195.0,194.1$, 157.6, 156.6, 156.4, 155.9, 155.5, 154.6, 153.1, 151.6, 142.1, 141.3, 141.1, 140.1, 136.5, 136.4, $136.3,136.2,126.0,125.9,125.6,125.3,125.2,125,0,125.0,124.9,124.8,124.8,124.7,124.1$, 
$120.6,120.5,120.5,120.5,116.9,116.7,116.2,115.9,114.9,114.4,114.4,113.9,110.6,109.6$, 109.5 ppm. HRMS calcd for $\mathrm{C}_{36} \mathrm{H}_{27} \mathrm{FeN}_{9} \mathrm{P}_{2} \mathrm{~F}_{12} \mathrm{~m} / z: 320.5864\left[\mathrm{M}-2 \mathrm{PF}_{6}\right]^{2+}$. Found 320.5856.

C3. The procedure was the same as for $\mathbf{C 1}$ using $\mathbf{L 3}$ (600 mg, $1.69 \mathrm{mmol}), \mathrm{FeCl}_{2}$ (70 $\mathrm{mg}, 0.56$ mmol) and potassium tert-butoxide (209 $\mathrm{mg}, 1.86 \mathrm{mmol})$ in $6 \mathrm{~mL}$ of DMF. The column chromatography was performed with water/acetone/ $\mathrm{KNO}_{3}(9 / 2 / 1)$ as eluent. A non-separable mixture of both $f a c$ - and $m e r-\mathbf{C 3}$ in 1:4 ratio $(153 \mathrm{mg}, 27 \%)$ as an orange solid was obtained. ${ }^{1} \mathrm{H}$ NMR $\left(400 \mathrm{MHz}, \mathrm{ACN}_{-} \mathrm{d}_{3}\right): \delta=8.42(\mathrm{~d}, J=8.55 \mathrm{~Hz}, 1 \mathrm{H}), 8.31(\mathrm{~d}, J=8.55 \mathrm{~Hz}, 1 \mathrm{H}), 8.18-8.06$ (m, 4H), 7.94-7.87 (m, 2H), $7.83(\mathrm{dd}, J=5.54,1.76 \mathrm{~Hz}, 1 \mathrm{H}), 7.46-7.39(\mathrm{~m}, 3 \mathrm{H}), 7.35(\mathrm{~s}, 1 \mathrm{H})$, $7.33(\mathrm{~s}, 1 \mathrm{H}), 7.29-7.24(\mathrm{~m}, 2 \mathrm{H}), 7.15(\mathrm{dd}, J=5.55,1.46 \mathrm{~Hz}, 1 \mathrm{H}), 7.11(\mathrm{dd}, J=6.05,1.08 \mathrm{~Hz}, 1 \mathrm{H})$, $7.02(\mathrm{t}, J=6.54 \mathrm{~Hz}, 1 \mathrm{H}), 6.96(\mathrm{t}, J=6.51 \mathrm{~Hz}, 1 \mathrm{H}), 6.77-6.62(\mathrm{~m}, 4 \mathrm{H}), 6.28(\mathrm{t}, J=6.24 \mathrm{~Hz}, 1 \mathrm{H})$, $6.22-6.07(\mathrm{~m}, 4 \mathrm{H}), 5.85(\mathrm{~d}, J=7.46 \mathrm{~Hz}, 1 \mathrm{H}), 5.55(\mathrm{~d}, J=7.46 \mathrm{~Hz}, 1 \mathrm{H}), 5.51(\mathrm{~d}, J=7.46 \mathrm{~Hz}, 1 \mathrm{H})$, $3.02(\mathrm{~s}, 3 \mathrm{H}), 2.92(\mathrm{~s}, 6 \mathrm{H}), 2.86(\mathrm{~s}, 3 \mathrm{H}) \mathrm{ppm} .{ }^{13} \mathrm{C} \mathrm{NMR}\left(100 \mathrm{MHz}, \mathrm{ACN}-\mathrm{d}_{3}\right): \delta=200.2,198.5$, $197.6,195.8,194.1,157.9,157.8,156.8,157,0156.7,155.8,153.3,151.8,141.5,140.8,140.5$, $139.4,133.2,133.2,133.0,132.9,125.6,125.5,125.0,125.0,124.7,142.7,124.4,123.7,122.9$, $122.8,122.8,122.7,122.4,122.3,121.4,121.2,119.8,119.7,119.7,116.7,116.6,116.6,116.1$, 116.0, 116.0, 115.7, 115.4, 12.3, 12.1, 12.1, 12.0 ppm. HRMS calcd for $\mathrm{C}_{39} \mathrm{H}_{33} \mathrm{FeN}_{9} \mathrm{P}_{2} \mathrm{~F}_{12} \mathrm{~m} / z$ : $341.6102\left[\mathrm{M}-2 \mathrm{PF}_{6}\right]^{2+}$. Found 341.6099.

\section{Computational details}

The Franck-Condon geometries ( $\mathrm{S}_{0} \mathrm{~min}$ ) of the $f a c$ and mer isomers of $\mathbf{C 1}$ and $\mathbf{C 2}$ have been optimized using the DFT/B3LYP functional in combination with the $6-31+\mathrm{G}(\mathrm{d}, \mathrm{p})$, as implemented in the GAUSSIAN 09 (D.01 revision) software package. ${ }^{37}$ This computational protocol has been able to describe the Franck-Condon geometry of related Fe(II) complexes bearing other NHC 
ligands. ${ }^{23,28,30-32,34}$ Note that only $\mathbf{C} \mathbf{1}$ and $\mathbf{C 2}$ complexes have been considered in the computational analysis since no significant differences, from a qualitative point of view, have been found in the photophysical properties of $\mathbf{C 2}$ and $\mathbf{C 3}$, given the similarities in the chemical structure.

Vertical absorption energies at the Franck-Condon region have been computed through the TDDFT method employing the Tamm-Dancoff approximation. ${ }^{38}$ The exchange correlation functional HCTH407 (hereafter, TD-HCTH) ${ }^{39}$ have been used given the good description of the excited states provided by this method in similar Fe-NHC systems as documented in previous works. $8,28,31,27,40$ The theoretical spectra reported in ESI have been obtained by sampling the nuclear density of the Franck-Condon region by means of a semiclassical Wigner distribution of 20 structures.

Right after, the excitation energies have been convoluted with Gaussian functions with a full width at half-length of $0.3 \mathrm{eV}$. A total number of 30 singlet-singlet electronic transitions have been computed for each geometry.

Note that the states displayed in Figure 7 are labelled according to the multiplicity of the state and the adiabatic energetic ordering without considering the nature of them. The nature of the excitations progressively evolves along the potential energy surfaces ${ }^{31}$ (see Figures S28-S30) and the nature of the excitations have been determined by computing the NTOs, ${ }^{41,42}$ via postprocessing of their density matrices obtained with the TD-HCTH method, using the NANCY_EX code. ${ }^{42,43}$ For the readers' convenience, we remind that NTOs may be considered as the best orbitals to describe a given electronic transition, and in contrast to the Kohn-Sham representation, often one or two couples of occupied/virtual orbitals are sufficient to fully describe the electronic density rearrangement in the excited state.

The $\mathrm{S}_{1}$ min geometries have been computed using the TD-DFT/HCTH method, whereas the $\mathrm{T}_{1}$ min and $\mathrm{Q}_{1}$ min structures have been optimized using the unrestricted DFT/HCTH ansatz. No 
symmetry or geometrical constrains have been imposed in the optimizations or single-point calculations.

\section{Femtosecond transient absorption spectroscopy}

In the transient absorption setup, an amplified $5 \mathrm{kHz}$ Ti: sapphire laser generates $30 \mathrm{fs} 0.5$ $\mathrm{mJ}$ pulses to pump a commercial optical parametric amplifier (TOPAS: Light Conversion), from which 50-60 fs pulses are derived to excite the samples: $370 \mathrm{~nm}$ for $\mathbf{C 1}$, and $470 \mathrm{~nm}$ for $\mathbf{C 2}$ and $\mathbf{C 3}$. A white light continuum is generated in a $2 \mathrm{~mm}$ thick $\mathrm{CaF}_{2}$ crystal, mounted on an oscillating loudspeaker to reduce photo-damage. The white light is optimised for minimised fluctuations (rms $<0.4 \%$ at $220 \mathrm{~Hz}$ ). The beam is split in two: the probe that is sent through the sample, and a reference beam is used for measuring and compensating the white-light intensity fluctuations. The polarization of the probe beam is set at magic angle $\left(54.7^{\circ}\right)$ with respect to the pump.

A $1 \mathrm{~mm}$ path length cuvette in fused silica contains the complexes dissolved in $\mathrm{CH}_{3} \mathrm{CN}$. Time-resolved spectra $\mathrm{I}(\lambda)$ are acquired in the range $\approx 300 \mathrm{~nm}$ wide window with an adjustable central wavelength as a function of pump-probe delay, by a combination of 25 $\mathrm{cm}$ focal length spectrometer (resolution $2 \mathrm{~nm}$ ) and a Peltier-cooled CCD with $220 \mathrm{~Hz}$ acquisition rate. A second chopper blocks the pump beam at $110 \mathrm{~Hz}$ and a home-made

software computes and displays the differential spectra $\Delta A=-\log _{10}\left(\frac{I_{\text {pump-on }}}{I_{\text {pump-off }}}\right)$. A solvent-only sample is measured, and the data are processed to (i) remove the background at negative delay times, (ii) the solvent Raman signal and the coherent interactions of the pump and probe in the cell, (iii) to correct for the group velocity dispersion of the probe beam, characterized in the solvent-only data set. The temporal resolution is characterized 
by the $50 \pm 5$ fs FWHM of the solvent Raman response. For more details see Ref 44 . The multi-exponential fit procedure is described in the SI.

\section{RESULTS AND DISCUSSION}

\section{Synthesis}

The ligand precursors $\mathbf{L 1}, \mathbf{L} 2$ and $\mathbf{L 3}$ required for the preparation of the target complexes have been prepared according to scheme 1. L1 was obtained in good yield by an aminationquaternarization sequence from 2-fluoropyridine. For the synthesis of $\mathbf{L} \mathbf{2}$ and $\mathbf{L 3}$ a construction of the imidazo[1,5-a]pyridine core was performed. ${ }^{45}$ An efficient cyclizing condensation involving 2-aminopyridine and 2-formyl or 2-acetyl pyridine afforded respectively $\mathbf{L} 2$ and $\mathbf{L 3}$ in good yields. The three target complexes $\mathbf{C 1}-\mathbf{C} 3$ were obtained in moderate yields by first reacting the ligand precursors with $\mathrm{FeCl}_{2}$, followed by addition of $t$ - $\mathrm{BuOK}$ as the base for generation of the carbenes. The parent compound $\mathbf{C O}$ was also synthesised for the sake of comparison following our previously reported procedure. ${ }^{32}$ 


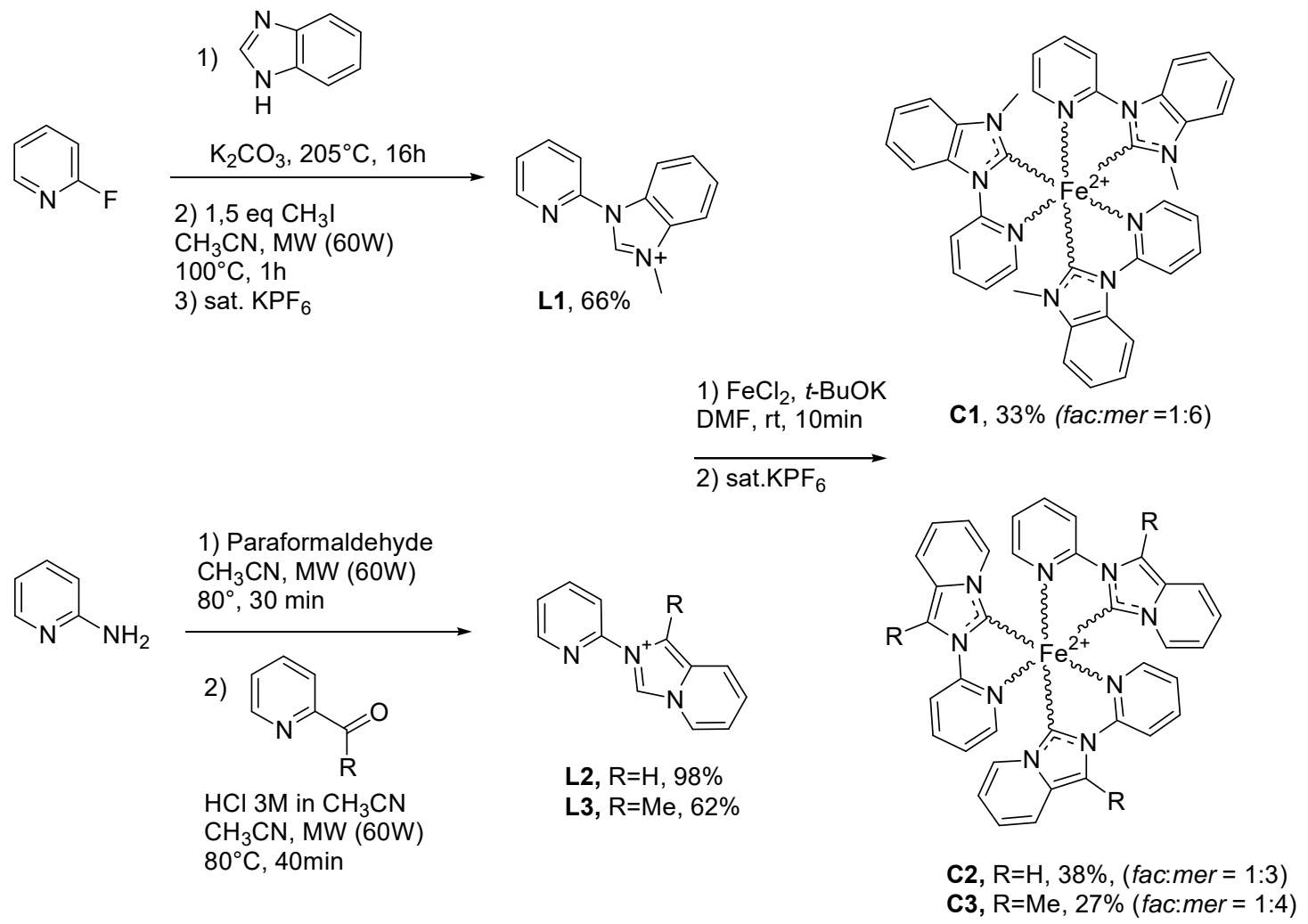

Scheme 1. Synthesis of ligands L1, L2 and L3 and the corresponding complexes C1, C2 and C3. Counter ion is $\mathrm{PF}_{6}{ }^{-}$in every case.

\section{Electronic and electrochemical properties}

The electronic and optical properties of the $\mathbf{C O}-\mathbf{C 3}$ complexes were investigated by means of steady-state UV-vis spectroscopy (Figure 2) and cyclic voltammetry (Table 1). 


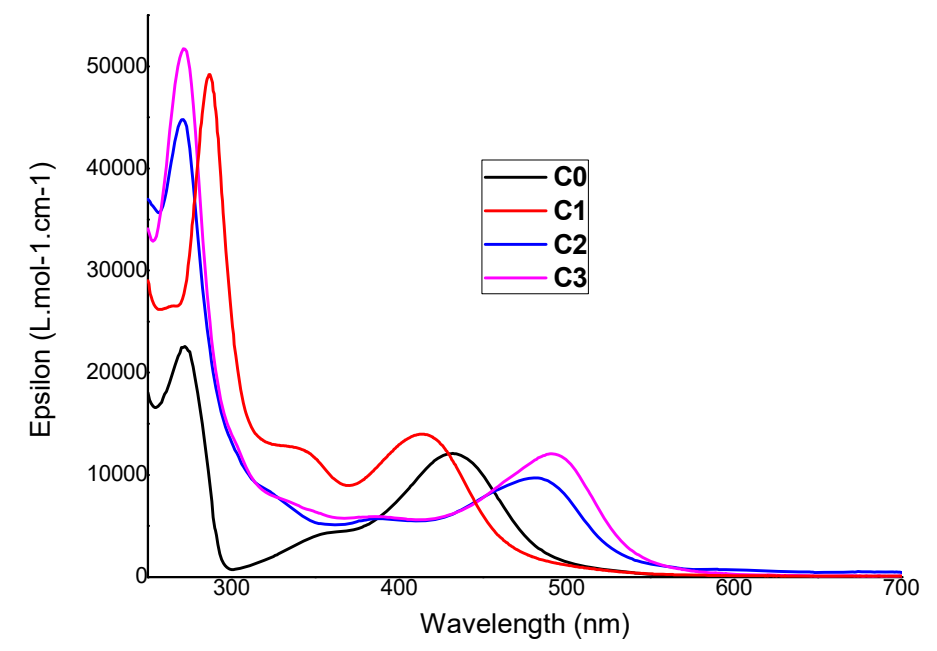

Figure 2. UV-Vis spectra of $\mathbf{C 0}-\mathbf{C 3}$ in acetonitrile. Only the $250-700 \mathrm{~nm}$ window is shown.

The UV/Vis spectra of all the complexes present three evident absorption bands. The bands in the UV region, below $300 \mathrm{~nm}$, correspond to $\pi-\pi^{*}$ transitions localized on the ligands, and are particularly intense. Two distinct broader and less intense bands are found at longer wavelengths, corresponding to MLCT transitions, with significant shifts of the absorption maximum $\left(\lambda_{\max }\right)$ as a function of the specific ligand. The weaker bands peaking in the 320-420 nm range are assigned to carbene-Fe MLCT transitions, ${ }^{27,28}$ while the bands with $\lambda_{\max }$ in the $430-600 \mathrm{~nm}$ area are due to the pyridine-Fe MLCT's. Comparison of the $\mathbf{C 0}$ and $\mathbf{C 1}$ absorption spectra shows that both MLCT bands are markedly blue-shifted when switching from the imidazolylidene (Im) to BIm due to the increased $\pi$-back donation induced by the annulation of the carbene moiety. ${ }^{28,32}$ On the contrary, the inclusion of ImP significantly red-shifts both the carbene-Fe $(30-35 \mathrm{~nm})$ and the pyridine-Fe (50-60 nm) absorption as compared to $\mathbf{C 0}$ and $\mathbf{C 1}$. Interestingly, the methyl substitution on ImP (C3) induces an additional slight red-shift with respect to the unsubstituted analogue (C2). 
The TD-DFT electronic spectra for $\mathbf{C 1}$ and $\mathbf{C 2}$ are shown in Figure S27 and are in reasonably good agreement with the experimental measurements. Computational results also allow the disentanglement of the different contributions of the fac and mer isomers: for $\mathbf{C 1}$, absorption of mer isomer is slightly red-shifted with respect to the $f a c$ analogue, whereas $\mathbf{C} 2$ exhibits an opposite trend. Indeed, the ${ }^{1}$ MLCT band of $f a c-\mathbf{C 2}$ is red-shifted $c a .100 \mathrm{~nm}$. This effect is masked in the experimental data by the fac:mer ratio of 1:3 and, as a matter of fact, absorption of mer isomer peaking at $\sim 500 \mathrm{~nm}$ dominates the spectrum of the $\mathbf{C 2}$ mixture. Natural transition orbitals (NTOs) confirm the ${ }^{1}$ MLCT nature of the bright states responsible for the absorptions, as displayed in Figure S28 of the Supporting Information.

The cyclic voltammetry data (Table 1 and Figure S12-S14) globally confirm the trends underlined by the absorption spectra with a decrease of the electrochemical gap going from $\mathbf{C O}$ to $\mathbf{C 2}$ and $\mathbf{C 3}$ in agreement with the observed redshifts. The positive domain corresponds to the reversible electron transfer of one electron per complex leading to the oxidation of $\mathrm{Fe}(\mathrm{II})$ to $\mathrm{Fe}(\mathrm{III})$. The oxidation potential is only slightly affected by switching from Im to ImP, while the further inclusion of a methyl group (C3) induces a decrease of the oxidation potential consistently with the observed redshift. On the contrary, the BIm unit results in an increase of the oxidation potential of $\mathbf{C 1}$ compared to $\mathbf{C} \mathbf{0}, \mathbf{C 2}$, and $\mathbf{C 3}$. Extending the conjugation upon annulation has been reported to increase the accepting character of $\mathrm{BIm}^{46}$ and $\mathrm{ImP}^{47}$ due to the delocalisation of the lone pairs of the nitrogen atoms, reducing the occupation of the $\mathrm{p}_{\pi}$ carbene orbital and allowing for an increased back-donation from the metal. However, these results highlight the remarkable differences in $\pi$ back-donation between both isomeric carbenes as evidenced by the distinct stabilization of the lower occupied iron orbitals (commonly referred to $\mathrm{t}_{2 \mathrm{~g}}$ for complexes with $\mathrm{Oh}$ symmetry), with BIm being the best $\pi$-acceptor. 
In the negative domain, two separate irreversible mono-electronic transfers are present for $\mathbf{C O}$ while for $\mathbf{C 1}, \mathbf{C 2}$ and $\mathbf{C 3}$ the two waves coalesce into a bielectronic reversible process. It can be assumed that the LUMO levels are stabilized by about $0.25 \mathrm{eV}$ by comparison with $\mathbf{C 0}$, suggesting that each electron is mainly injected into ImP or BIm moiety instead than pyridine as for $\mathbf{C 0}$. The increased conjugation of ImP and BIm would nicely justify the effective stabilisation of the LUMO levels in comparison to that associated to the pyridine moiety.

Table 1. Optical and electrochemical properties of the studied complexes

\begin{tabular}{|c|c|c|c|c|}
\hline & $\begin{array}{l}\lambda_{\text {abs-max }}(\mathrm{nm}) \\
\left(\varepsilon\left(\mathrm{M}^{-1} \cdot \mathrm{cm}^{-1}\right)\right)^{\mathrm{a}}\end{array}$ & $\begin{array}{l}\mathrm{E}_{o x}\left(\mathrm{Fe}^{\mathrm{III}} / \mathrm{Fe}^{\mathrm{II}}\right) \\
(\mathrm{V} / \mathrm{SCE})^{\mathrm{b}}\end{array}$ & $\begin{array}{l}\text { Eredl } \\
(\mathrm{V} / \mathrm{SCE})\end{array}$ & $\Delta \mathrm{E}(\mathrm{eV})^{\mathrm{c}}$ \\
\hline \multirow{2}{*}{$\mathrm{CO}$} & $358(4300)$ & \multirow{2}{*}{0.67 (rev) } & -1.88 (irrev.) & 2.55 \\
\hline & $432(12100)$ & & -1.93 (irrev) & 2.60 \\
\hline \multirow[b]{2}{*}{$\mathrm{C} 1$} & $337(12700)$ & \multirow[b]{2}{*}{0.87 (rev) } & \multirow[b]{2}{*}{$-1.63(\mathrm{rev})$} & \multirow[b]{2}{*}{2.50} \\
\hline & 414 (13980) & & & \\
\hline \multirow[b]{2}{*}{$\mathrm{C} 2$} & $394(5670)$ & \multirow[b]{2}{*}{0.70 (rev) } & \multirow[b]{2}{*}{$-1.68(\mathrm{rev})$} & \multirow[b]{2}{*}{2.38} \\
\hline & $481(9700)$ & & & \\
\hline \multirow{2}{*}{$\mathbf{C 3}$} & $389(5910)$ & \multirow{2}{*}{0.61 (rev) } & \multirow{2}{*}{$-1.66(\mathrm{rev})$} & \multirow{2}{*}{2.27} \\
\hline & $490(12100)$ & & & \\
\hline
\end{tabular}

${ }^{a}$ Measured in $\mathrm{CH}_{3} \mathrm{CN}$ at $25{ }^{\circ} \mathrm{C}$. ${ }^{b}$ First oxidation potential. Potentials are quoted $v s$ SCE. Under these conditions, $\mathrm{E}_{1 / 2}(\mathrm{Fc}+/ \mathrm{Fc})=0.39 \mathrm{~V} / \mathrm{S}$.C.E. Recorded in $\mathrm{CH}_{3} \mathrm{CN}$ using $\mathrm{Bu}_{4} \mathrm{~N}^{+} \mathrm{PF}_{6}^{-}(0.1 \mathrm{M})$ as supporting electrolyte at $100 \mathrm{mV} . \mathrm{s}^{-1} .{ }^{\mathrm{c}}$ Electrochemical band gap $\left(\Delta \mathrm{E}=\mathrm{E}_{o x}-\mathrm{E}_{\text {redl }}\right)$

\section{Time-resolved spectroscopy}

We investigated $\mathbf{C 1}, \mathbf{C 2}$ and $\mathbf{C 3}$ with femtosecond transient absorption spectroscopy (TAS) in acetonitrile at room temperature. With the background of our first publication on complex $\mathbf{C O}$ and 
a fac-only version of it $^{31,32}$ these experiments were expected to reveal an extension of the excited state lifetime due to the fusion of a phenyl group to the imidazole part of the ligands, as observed for tridentates. Two main questions arise: How do these modified ligands change the excited state relaxation? Is the scenario of parallel population and decay of two excited states reported for $\mathbf{C O}$ and $f a c$-only $\mathbf{C O}$ also valid for $\mathbf{C 1}-\mathbf{C} 3$ ?

Transient absorption measures the photo-induced changes of the optical density or absorbance $\Delta \mathrm{A}$ and can be expressed by:

$\Delta A(\lambda, t)=d \sum_{i} \epsilon_{i}(\lambda, t) \Delta c_{i}(t)$

with $d$ being the sample thickness. The sum runs over all molecular electronic states $i$ whose population is changed by the laser excitation at $\mathrm{t}=0$, and the subsequent photoreactions and their kinetics, as expressed by the molar concentration change $\Delta c_{i}(t)$. The latter is positive for excited state population, leading to positive excited state absorption (ESA), and negative for the ground state population, $\Delta c 0(t=0)<0$, due to the partial depletion of the ground state by the laser excitation leading to ground state bleach (GSB) signals.

As an example, Figure 3 displays the transient absorption spectra of $\mathbf{C 2}$ for time delays covering the first 12 ps after excitation with a $40 \mathrm{fs}$ pulse at $470 \mathrm{~nm}$. A $20 \mathrm{~nm}$ spectral range around this wavelength is dominated by scattered pump laser light, and therefore not displayed. A broad ESA band dominates the signal for $\lambda>520 \mathrm{~nm}$, while GSB is dominant for shorter wavelengths, leading to $\Delta \mathrm{A}<0$. The grey area is the inverted ground state absorption spectrum (SSA), normalised such as to fit the GSB amplitude at $485 \mathrm{~nm}$. The neg. $\Delta \mathrm{A}$ portion is spectrally significantly sharper than the SSA, indicating, according to eq. (1), the contribution of ESA components, as is clearly visible for $\lambda>520 \mathrm{~nm}$, but hidden for shorter wavelengths where GSB dominates. Such an overlap of 
excited state and ground state signals is a general limitation of TAS, leading to uncertainties as will be discussed below.

The time-dependent $\Delta \mathrm{A}$ spectra of $\mathbf{C 3}$ are like the one of $\mathbf{C 2}$ (Fig. S15). For $\mathbf{C 1}$, the ESA/GSB pattern is obviously blue-shifted according to the SSA (Fig. 2). The dynamic changes of the ESA spectra are more pronounced than for $\mathbf{C 2}$ and $\mathbf{C 3}$, and resemble the evolution of $\mathbf{C 0}{ }^{31}$

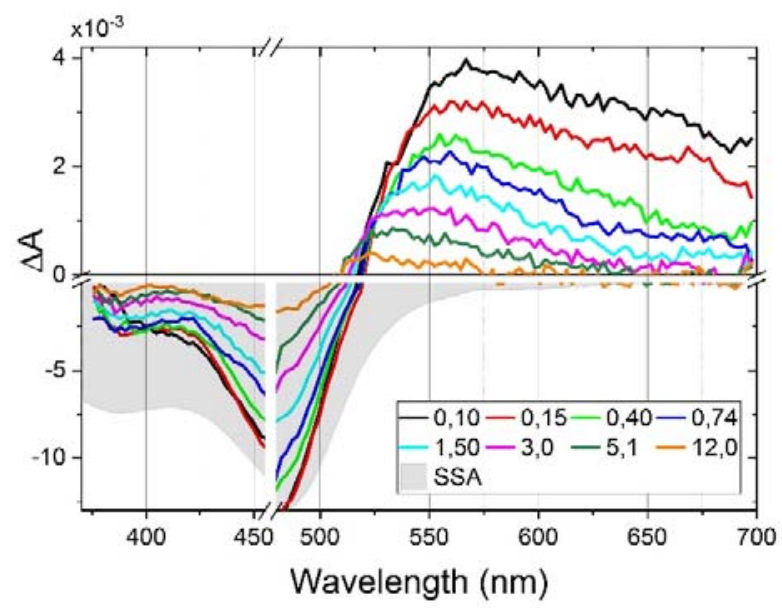

Figure 3. Transition absorption spectra of complex $\mathbf{C 2}$ during the first 12 ps. Shaded area is the inverted steady-state absorption spectrum (SSA) scaled to match the GSB max. Note the break in the $y$-axis, and the different scales for the positive and negative signals. The $460-480 \mathrm{~nm}$ range is disregarded due to excessive pump light scattering. The progressive change in the spectral shape of the positive ESA is discussed in terms of the superposition and population of two excited states $\mathrm{T}_{1}$ and $\mathrm{T}_{2}$. The signal decays dominantly on $\mathrm{a} \approx 3 \mathrm{ps}$ time scale.

A detailed inspection of the spectral features of $\mathbf{C 2}$ reveals important information about the excited state evolution. We see that ESA and GSB decay on three different time scales. The ESA amplitude decays by half already in the first $0.4 \mathrm{ps}$, and the spectral width reduces since the decay is most prominent for $\lambda>600 \mathrm{~nm}$. The negative $\Delta \mathrm{A}$ part decreases by not more than $10 \%$ during this time. On a $\approx 3$ ps time scale both ESA- and GSB-dominant parts decay by $\approx 50 \%$, and the ESA 
spectrum slightly blue shifts, as can also be seen by the ESA-GSB crossover point $(\Delta \mathrm{A}=0)$ shifting by $5 \mathrm{~nm}$ to the blue. A third stage of $\Delta \mathrm{A}$ decay proceeds on a slower time scale of $\approx 10 \mathrm{ps}$, with the ESA further evolving in shape and energy. Qualitatively, the same behaviour is observed for C1 and $\mathbf{C 3}$ (Fig. S15).

Figure 4 depicts kinetic traces for all four complexes $\mathbf{C} \mathbf{0}-\mathbf{C} 3$ at selected wavelengths. A quick glance shows that the BIm and ImP moieties have only minor effects on the excited state kinetics. In particular, the kinetic traces in the top and bottom panels highlighting dominant excited state decay (ESA) and ground state repopulation (GSB) almost overlay. The middle panel shows the GSB/ESA crossover region, highlighting the above described spectral blue shift. On a timescale of 2-3 ps, the positive ESA contribution rises turning the signal from dominant GSB $(\Delta \mathrm{A}<0)$ to dominant $\operatorname{ESA}(\Delta \mathrm{A}>0)$.

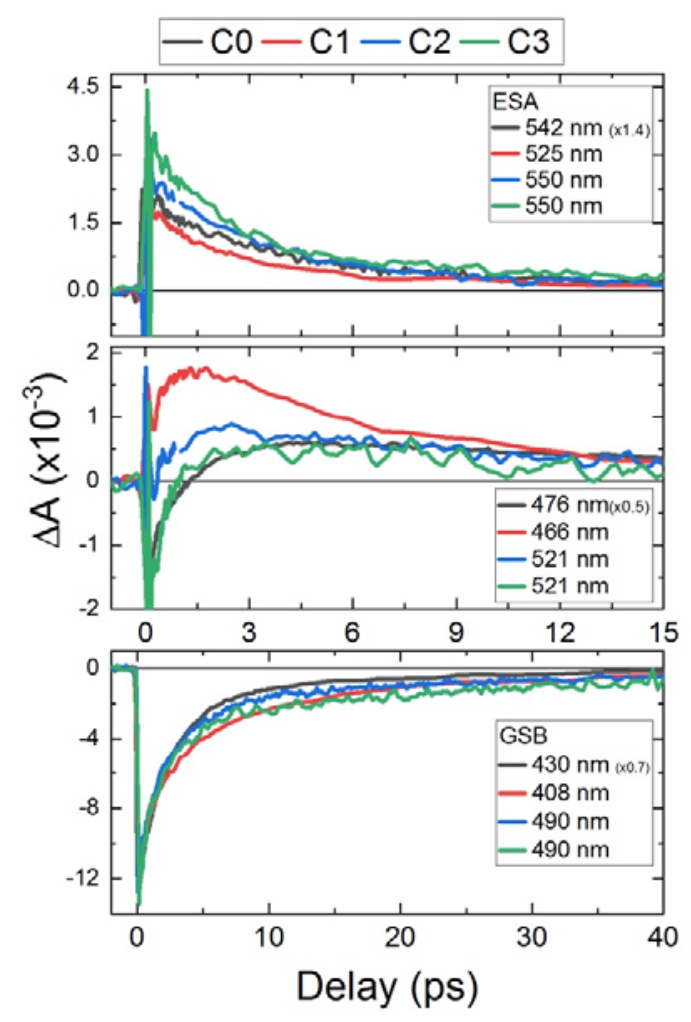


Figure 4. Comparison of kinetic traces for complexes $\mathbf{C O}-\mathbf{C} 3$ at selected wavelengths (CO-black; C1-red; C2-blue; C3-green). Top: early-delay ESA maximum, middle: GSB-ESA crossover region, bottom: long-wavelength GSB tail.

The kinetic transients of $\mathbf{C 2}$ are reported in Figure 5 together with 3-exponential fits, convoluted by the instrument response function (50 fs FWHM, see SI for details). Plotted on a semi-log scale, the relative contributions of the three different time scales are particularly apparent for the GSB plotted with an inverse sign for the logarithmic intensity scale (Fig. 5A). A straight line is plotted as a guide-to-the eye, the slope of which corresponds to a $\approx 3$ ps decay time, but a faster subpicosecond decay and a slower $>10$ ps decay time are clearly visible. For the dominant ESA wavelengths (Fig. 5B), the guide-to-the-eye indicates that the decay is wavelength dependent, with faster decays observed for longer wavelengths, consistent with the qualitative inspection of the time-resolved spectra (Fig. 3).

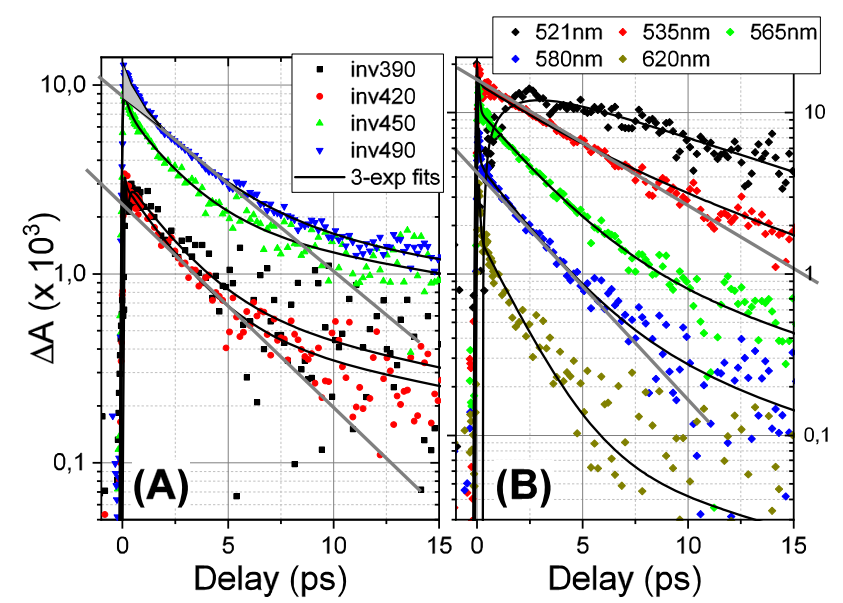

Figure 5. Kinetic transients for $\mathbf{C 2}$ and 3-exponential fits in the GSB (A) and dominant ESA(B) regions, plotted on logarithmic intensity scale, highlighting the multi-exponential decay. (A): Selected traces of the GSB region, plotted with inverted sign. Lines correspond to a 3.0 ps decay. (B): Selected traces from the ESA long-wavelength region. 
All kinetic traces can be well fitted by a sum of three exponentials with wavelength-dependent amplitudes and decay constants, $\sum_{i=1}^{3} A_{i}(\lambda) e^{-t / \tau_{i}(\lambda)}$, convoluted with a Gaussian instrument response function (width $50 \mathrm{fs}$ ). The results of these fits are plotted in Figure 6A, and detailed plots of the fit curves and their residuals can be found in the SI, for $\mathbf{C 1}$ and $\mathbf{C 3}$ (Fig. S16 and S17). Since the spectral and kinetic evolution is very similar among the complexes, we discuss the fit results only for C2. The shortest decay time $\tau_{1}$ is found in the $0.1-0.2$ ps range and shows slightly larger values $(0.4 \mathrm{ps})$ only for the range of maximum negative $\Delta \mathrm{A}(450-500 \mathrm{~nm})$, where the signal-tonoise ratio is highest. The amplitudes of $\tau_{1}$ are not displayed since their values are strongly wavelength-dependent and no clear interpretation can be given. For almost all wavelengths, $\tau_{2}$ is the dominant decay component $\left(\mathrm{A}_{2}>3 \mathrm{xA}_{3}\right)$. Its value is slightly wavelength-dependent, with an average value of $\tau_{2}=2.5 \pm 0.3 \mathrm{ps}$, and dropping from 2.5 to $1.5 \mathrm{ps}$ in the red. In the crossover region $(520-540 \mathrm{~nm})$, the fitted times are the results of compensating rising and decaying exponentials and thus fluctuate strongly, without any significance for the actual excited state lifetimes.
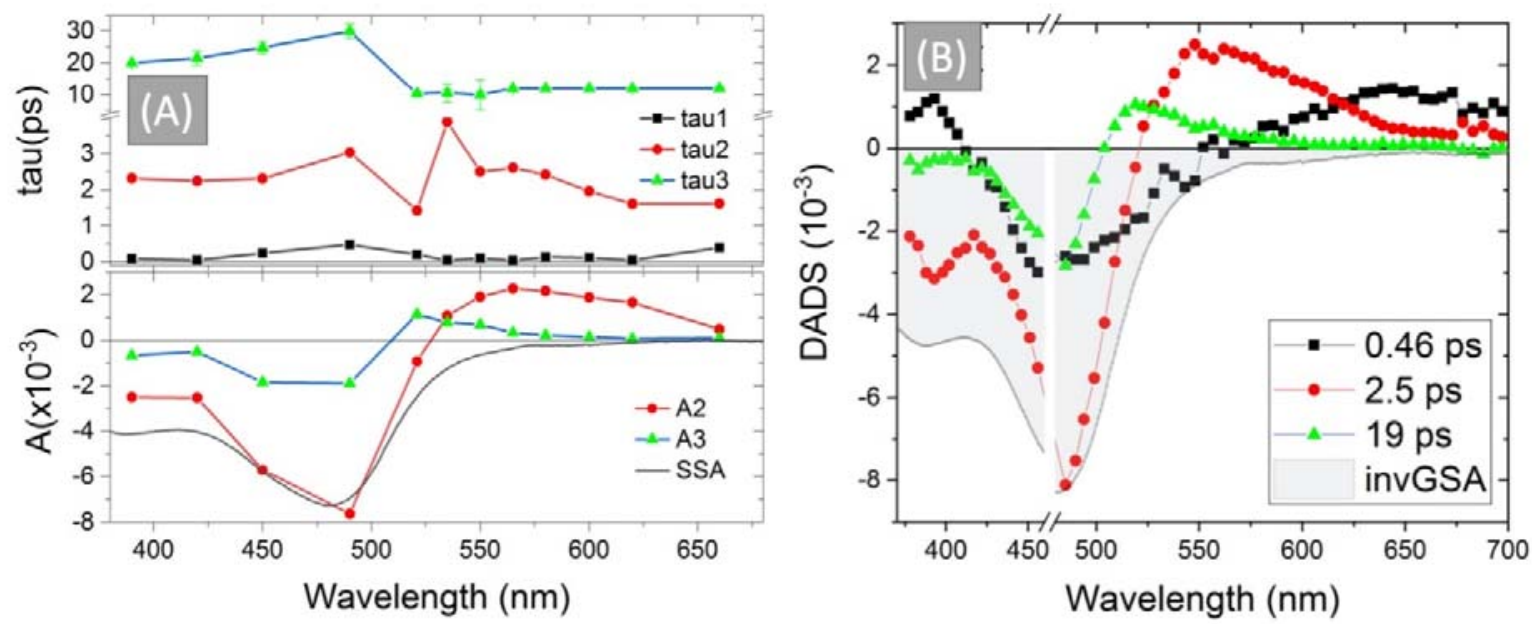
Figure 6. Results of 3-exponential fittings for C2. A-Top: Values of the 3 wavelength-dependent time constants. The symbol size indicates typical fit error bars. $\tau_{3}$ is kept fixed at $12 \mathrm{ps}$ for $\lambda \geq 580$ nm. A-Bottom: Decay amplitudes $A_{2}$ and $A_{3}$. B: Decay-associated difference spectra (DADS) obtained with a global fit approximation. The inverted and scaled ground state absorption spectra (SSA/invGSA) are indicated for comparison.

The spectral shape of $A_{2}$ is in good agreement with the time-resolved spectra, displaying a dominant ESA for $\lambda>520 \mathrm{~nm}$. For $\tau_{3}$, the fits give values of $20-30$ ps in the GSB region $(\lambda<500$ $\mathrm{nm}$ ), and around $10 \mathrm{ps}$ in the 520-550 nm ESA region, where the amplitude is large enough to determine this component reliably. The spectral distribution of $\mathrm{A}_{3}$ agrees with the long-delay $\Delta \mathrm{A}$ spectra, for $\mathrm{t}>10 \mathrm{ps}$ (Fig. 3), with a maximum signal at $520-525 \mathrm{~nm}$. Since the spectral shifts and the wavelength-dependence of the lifetimes are relatively small, we have performed a global analysis assuming wavelength-independent average lifetimes, using the shareware software OPTIMUS. ${ }^{48}$ The validity of wavelength-independent average lifetimes is assessed in detail in the SI. It is found that the fit quality is very high except for the wavelengths of ESA/GSB crossover, displaying a dynamically shifting point of $\Delta \mathrm{A}=0$. The results are displayed in Fig. $6 \mathrm{~B}$ and show that the shape and positions of the maxima of the decay-associated difference spectra (DADS) agree with the $\mathrm{A}_{2}$ and $\mathrm{A}_{3}$ distributions obtained by individual wavelength fits (Fig. 6A). For all the complexes $\mathbf{C 1}$ to $\mathbf{C 3}$, the average lifetimes given in Table 2 are derived from such a global fit approach.

Table 2. Values of the three decay times and the $A_{2} / A_{3}$ ratio at the wavelength of maximum GSB for the four complexes C0-C3. Values extracted from global fits for $\mathbf{C 1}-\mathbf{C} 3$ (cf. SI).

\begin{tabular}{lcccc} 
Complex & $\tau_{1}(\mathrm{ps})$ & $\tau_{2}(\mathrm{ps})$ & $\tau_{3}(\mathrm{ps})$ & $\mathrm{A}_{2} / \mathrm{A}_{3}$ \\
\hline $\mathbf{C 0}^{\mathrm{a}}$ & $0.5 \pm 0.1$ & $2.8 \pm 0.5$ & $17 \pm 3$ & 7.0
\end{tabular}




$\begin{array}{lllll}\text { C1 } & 0.6 \pm 0.1 & 3.1 \pm 0.5 & 15 \pm 3 & 1.3 \\ \text { C2 } & 0.4 \pm 0.1 & 2.5 \pm 0.5 & 19 \pm 3 & 4.0 \\ \text { C3 } & 0.3 \pm 0.1 & 1.8 \pm 0.5 & 24 \pm 3 & 2.3\end{array}$

${ }^{\text {a }}$ Taken from ref. ${ }^{32}$.

The critical point is now to build a reaction scheme involving the three lifetimes. The subpicosecond $\tau_{1}$ is usually assigned to the transition from the optically excited ${ }^{1}$ MLCT to ${ }^{3}$ MLCT and vibrational relaxation of the latter, reflected in the ultrafast decay of ESA for the longest wavelengths. In C0, this phase of relaxation leads to a rise of the ESA signal at shorter wavelength $\mathrm{s}^{31}$ and a similar behaviour is pronounced in $\mathbf{C 1}$, here in the $500-550 \mathrm{~nm}$ range (Fig. $6 \mathrm{~B}$, and fits in Figs. S24 and S25), indicating that a sequential scheme is appropriate.

Since the ratio of amplitudes $\mathrm{A}_{2} / \mathrm{A}_{3}$ corresponds approximately to the $m e r$-to-fac isomer ratio (see experimental section), one is tempted to attribute the faster $\tau_{2}$ to $m e r$ and $\tau_{3}$ to the $f a c$ isomer. However, as we have shown in our previous publication on the pure fac- and a dominant merforms of C0, both decay components are present no matter what isomer content. ${ }^{31}$ Hence, interpretation of $\tau_{2}$ and $\tau_{3}$ and their related amplitude spectra requires a more careful inspection since, in the past, we have given different interpretations for seemingly similar spectral evolutions. Indeed, while in our recent work on tridentate complexes with pyrazine ligands we derived a scenario based on a single triplet excited state, with $\tau_{3}$ being its lifetime and $\tau_{2}$ representing slow picosecond structural relaxation, ${ }^{30}$ the bidentate data for $\mathbf{C O}$ and its fac-only version revealed the population of two triplet states with $\tau_{2}$ and $\tau_{3}$ being their respective lifetimes. ${ }^{32}$ Both scenarios differ, however, in two major points. For instance, for the former mono-state scenario: a) the amplitude of $\tau_{3}$ is largely dominant, and $b$ ) the amplitude of $\tau_{2}$ is close to zero or even positive in 
the short wavelength part of the GSB $(<400 \mathrm{~nm}) .{ }^{30}$ On the contrary, for the bidentate complexes under study, we observe $\mathrm{A}_{2}>\mathrm{A}_{3}$ and $\tau_{3}$ showing up as an additional excited-to-ground state relaxation process since the amplitude of $A_{3}$ is significant for all wavelengths below $450 \mathrm{~nm}$. Note also that $\mathrm{A}_{3}$ follows the profile of the inverse SSA spectrum (Fig. 6).

In summary, as for $\mathbf{C O}$ and its fac-only version, the TAS data are consistent with the existence of two excited triplet states, $\mathrm{T}_{1}$ and $\mathrm{T}_{2}$, populated via relaxation from ${ }^{1} \mathrm{MLCT}$ and subsequent vibrational cooling during $\tau_{1}$, and decaying in parallel back to the ground state $\mathrm{S}_{0}$, according to the following scheme:

$$
{ }^{1} \mathrm{MLCT}^{+} \stackrel{<I R F}{\longrightarrow}\left\{\begin{array} { c } 
{ { } ^ { 3 } \mathrm { MLCT } _ { 1 } } \\
{ { } ^ { 3 } \mathrm { MLCT } _ { 2 } }
\end{array} { } ^ { + } \stackrel { \tau _ { 1 } } { \rightarrow } \left\{\begin{array}{l}
T_{1} \stackrel{\tau_{3}}{\rightarrow} S_{0} \\
T_{2} \stackrel{\tau_{2}}{\rightarrow} S_{0}
\end{array}\right.\right.
$$

Here, the "+" index denotes vibrationally excited electronic states, inevitably present in the first hundred of femtoseconds after laser excitation. In our previous paper, ${ }^{31}$ we assigned the $\mathrm{A}_{2} / \mathrm{A}_{3}$ ratio at the GSB maximum to the ratio of populations of $T_{2} / T_{1}$. However, due to the overlap of ESA and GSB and since the ESA absorption coefficients of $T_{1}$ and $T_{2}$ are unknown, an accurate determination of the excited state branching ratio is not possible.

The nature of the states $\mathrm{T}_{1}$ and $\mathrm{T}_{2}$, namely MLCT vs. MC character, and the impact of isomerism, namely fac vs. mer, is rationalized in the following section via molecular modelling of the excitedstate topology and relaxation pathways.

Since the global fitting procedure can be applied to a good approximation, we performed simulations of a purely sequential relaxation scenario. An analysis of the species-associated difference spectra (SADS) reveals, under this assumption and after subtraction of the GSB component, that the absorption spectrum decaying with $\tau_{3}$ is actually very close to the GSA, displaying only a small red-shift of 8-10 $\mathrm{nm}$ with respect to the latter (Fig. S22). This finding leads 
us to suggest a second alternative reaction scenario, with one excited state $\mathrm{T}_{1}$, decaying within $\tau_{2}$ $=2-3 \mathrm{ps}$, and the longer-lived species actually being assigned to an unrelaxed ground state, $\mathrm{S}_{0}{ }^{+}$. The $\tau_{3}$ component would then be related to vibrational and dielectric relaxation of the molecules in the ground state. Such a scenario is commonly observed for ultrafast excited state reactions, where a large excited state excess energy $(>1 \mathrm{eV})$ is almost impulsively released into the ground state, leading to a non-equilibrated ground state population, which decays within several picoseconds. ${ }^{49,50}$ This is the most plausible interpretation, but not a definitive proof the nature of $\mathrm{S}_{0}{ }^{+}$. Scheme 3 summarises this alternative purely sequential scheme.

$$
{ }^{1} \mathrm{MLCT}^{+} \stackrel{<I R F}{\longrightarrow}{ }^{3} \mathrm{MLCT} T^{+} \stackrel{\tau_{1}}{\longrightarrow} T_{1} \stackrel{\tau_{2}}{\longrightarrow} S_{0}{ }^{+} \stackrel{\tau_{3}}{\longrightarrow} S_{0}
$$

\section{Molecular modeling of the excited-state decay}

Analysis of the excited state reveals that, as for $\mathbf{C 0},{ }^{31,32,34}$ the lowest-lying triplet states of $\mathbf{C 1}$ and $\mathbf{C 2}$ have ${ }^{3} \mathrm{MLCT}$ character at regions close to the Franck-Condon as well as to $\mathrm{S}_{1}$ min area, whereas further relaxation of the triplet manifold is driven by the elongation of a single $\mathrm{Fe}-\mathrm{N}$ bond up to distances larger than $3.2 \AA$ leading to spin-crossover regions with the ground state $\mathrm{S}_{0}$, with dominant ${ }^{3} \mathrm{MC}$ character for the triplet states. This is illustrated in Figures $7 \& 8$, and in the SI (Figs. S29-S31 and Table S1). 

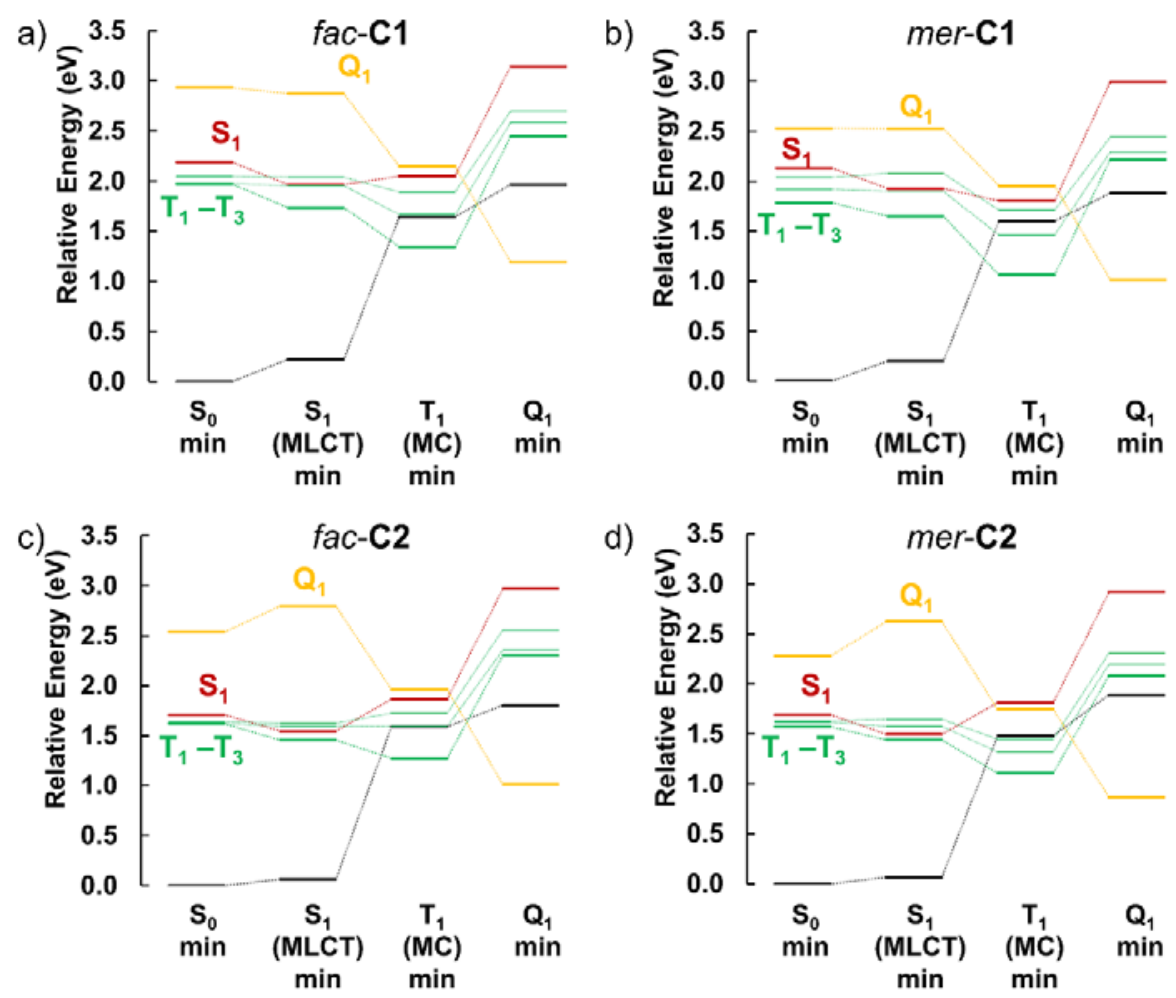

Figure 7. Relative energies of the most relevant electronic states at different equilibrium geometries for a) $f a c-\mathbf{C 1}$, b) $m e r-\mathbf{C 1}$, c) $f a c-\mathbf{C 2}$, and d) $m e r-\mathbf{C 2}$. 


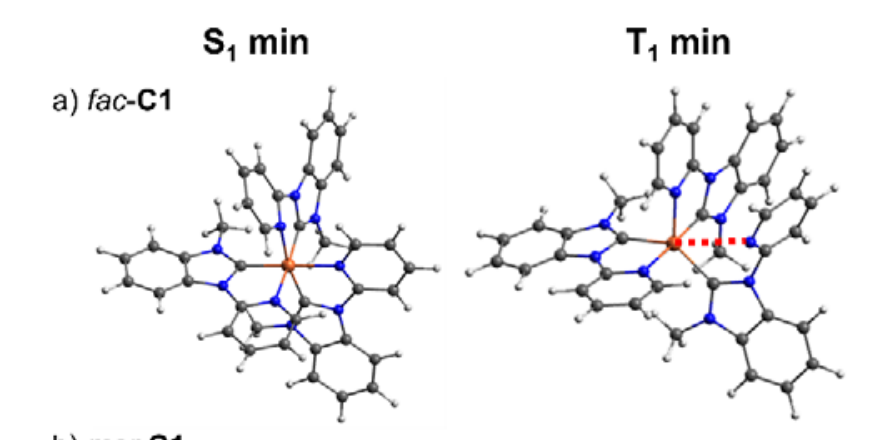

b) $m e r-\mathbf{C 1}$

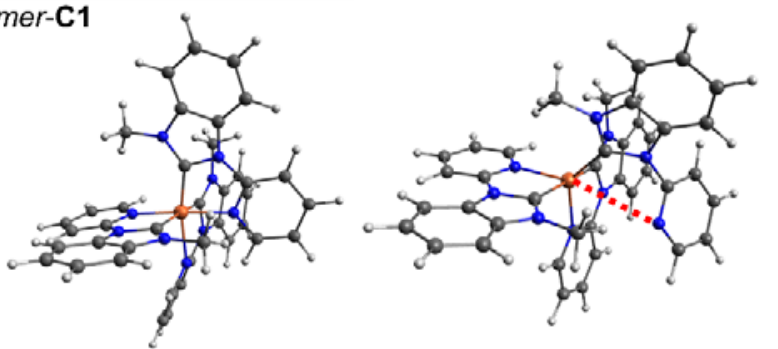

c) fac-C2
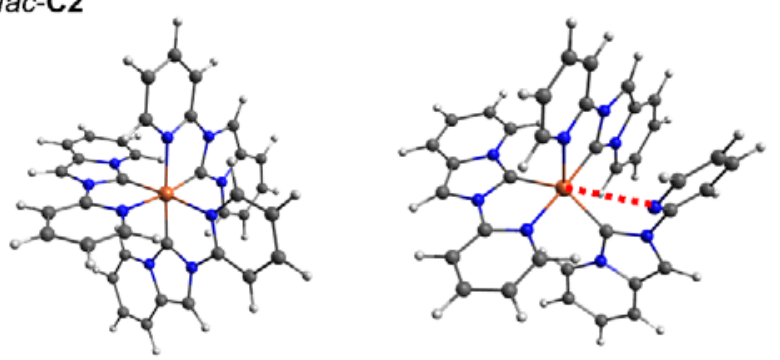

d) mer-C2
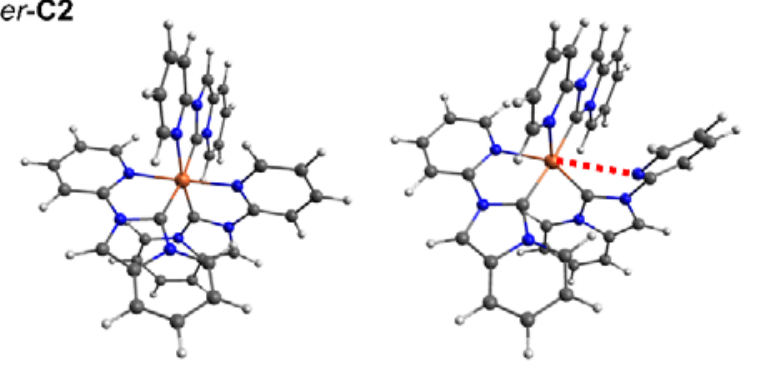

Figure 8. $S_{1} \min$ and $T_{1}$ min optimized structures of the complexes. Red dashed lines highlight the Fe-N elongated bonds $(>3.2 \AA)$ in the triplet state.

These data reveal an adiabatic progression from ${ }^{3} \mathrm{MLCT}$ to ${ }^{3} \mathrm{MC}$ evidencing $\mathrm{T}_{1} / \mathrm{S}_{0}$ and $\mathrm{T}_{2} / \mathrm{S}_{0}$ singlet-triplet crossing regions close to the $\mathrm{T}_{1}$ min equilibrium geometries that mediate the non- 
radiative decay to the ground state. The spin-crossover character of these $T_{1}$ min regions and the energy splitting between the $T_{1}$ and $T_{2}$ states (see Fig. 7) suggest an excited-state decay scenario very similar to the $\mathbf{C O}$ prototype, for which the triplet potential energy surfaces and the minimum energy paths were determined in much detail. ${ }^{31,32,34}$ Therefore, we can safely identify two main deactivation channels, namely a fast $\mathrm{T}_{2}$ pathway (few picoseconds) and a slower $\mathrm{T}_{1}$ channel (tens of picoseconds), the longer trapping of the excited state in the $\mathrm{T}_{1}$ channel is ascribed to the larger spin-crossover regions as discussed in detail elsewhere. ${ }^{32}$

The energy diagrams shown in Figure 7 also allow to compare the profiles for the different isomers of $\mathbf{C 1}$ and $\mathbf{C 2}$. For $f a c-\mathbf{C 1}$ (Fig. 7a), the $\mathrm{T}_{1}$ state at the corresponding $\mathrm{T}_{1}$ equilibrium geometry lies at a relative energy of $1.34 \mathrm{eV}$, whereas in mer-C1 (Fig. 7b) this energy is lower, $1.06 \mathrm{eV}$. The same trend is observed for $\mathbf{C 2}$ (Fig. $7 \mathrm{~b}$ and c) $(1.28 \mathrm{eV}$ for $f a c-\mathbf{C 2} \mathrm{vs} .1 .11 \mathrm{eV}$ for mer-C2). This finding suggests that, assuming very similar potential energy surfaces as those of C0, ${ }^{31,32}$ mer isomers will decay preferentially via $\mathrm{T}_{2}$, since the triplet profiles are steeper and the corresponding ${ }^{3} \mathrm{MC}$ minima lie at lower energies. In addition, the $\mathrm{T}_{1}-\mathrm{T}_{2}$ splitting is larger for the mer isomers (see Fig 7): this is especially relevant at the FC and $\mathrm{S}_{1}\left({ }^{1} \mathrm{MLCT}\right)$ min regions since the $\mathrm{T}_{1} / \mathrm{T}_{2}$ branching ratio is determined at these areas, as previously discussed for $\mathbf{C O}{ }^{32}$

Regarding the possible role of quintet states, the energy diagrams displayed in Figure 7 evidence a profile similar to that of $\mathbf{C} \mathbf{0}$, in which a significant participation of the $\mathrm{Q}_{1}$ state was discarded on the basis of the energy barriers found to access the triplet-quintet crossing points along the potential energy surfaces. Thus, an analogous situation is expected for the current $\mathbf{C 1}$ and $\mathbf{C} 2$ complexes as also confirmed by TAS analysis discussed above. 


\section{CONCLUSION}

The present paper reports our recent results on the synthesis of novel complexes of Fe(II) with two types of pyridyl-NHC bidentate ligands. The prototypical imidazolylidene carbene moieties are substituted by benzimidazolylidene (BIm) and imidazo[1,5-a]pyridine-3-ylidene (ImP) units, providing dominantly mer isomers. The combined experimental and computational study focusses on the effect of these substitutions on the spectroscopic properties and on the excited state lifetimes (ESL) and relaxation pathways, since the aim of these substitutions is to extend the ESL in the context of designing photo-sensitizing and photo-functional complexes with earth-abundant metals.

While the substitutions have significant effects on the energies of the frontier orbitals, as measured by cyclic voltammetry, and on the absorption properties, the excited state lifetimes and photoresponse are only marginally affected. As for the previously published dominantly fac and mer isomers of $\left[\mathrm{Fe}(\mathrm{PyIm})_{3}\right]^{2+}$, the experimental transient absorption data are best described by a parallel population and decay of two excited states $\mathrm{T}_{2}$ and $\mathrm{T} 1$, decaying with $2-3$ and $15-18$ ps lifetimes, respectively, according to the excited and ground state energetics found by TD-DFT calculations. The latter lifetime appears with smaller amplitude in the $\Delta \mathrm{A}$ signal, which may reflect a smaller population in $T_{1}$ as compared to $T_{2}$. But it may also be due to the increased overlap and thus compensation of GSB and ESA in the case of $\mathrm{T}_{1}$ (cf. Fig. S20).

The present study teaches us an important lesson, since the BIm substitution, which almost doubled the ESL for tridentate Fe(II) complexes with four carbenes, ${ }^{27,28,30}$ turns out to be ineffective for the bidentate ligands. The initial design idea, to stabilize the MLCT orbitals via extended conjugation, 
is validated by electrochemistry, consistent with shifts of the ground state absorption spectra, but it is not operational in extending the ESL. This conclusion holds whatever photoresponse scheme ( 2 or 3 ) is actually at work for these homoleptic bidentate complexes. One realizes that the molecular parameters such as enhanced ligand field splitting and stabilization of the MLCT energies, which were considered to be critical for the initial work fueling the development of NHC ligands for $\mathrm{Fe}(\mathrm{II}),{ }^{8,21,28-30,33}$ are not relevant any more in the present complexes with 3 or $4 \mathrm{Fe}-$ carbene bonds. So, which parameter rules the excited state relaxation, and the ESL, i.e. the time it takes to reach the ${ }^{3} \mathrm{MC}-\mathrm{S}_{0}$ spin crossover region?

It is clear from previous computational work and ours that, in the presence of a pyridine ligand, the elongation of the Fe- $\mathrm{N}$ bond is the key degree of freedom. ${ }^{31}$ In other words, an increased stiffness is likely to create an excited state barrier leading to an increased ESL. This was realized already by the latest work of the McCusker group, ${ }^{51,52}$ and it explains the difference between our bidentate and tridentate complexes. As in the former, the Fe-N bond is more flexible, there is less energetic penalty for reaching the ${ }^{3} \mathrm{MC}-\mathrm{S}_{0}$ crossing, and the effect of ligand substitutions does play a minor role for extending the ESL. Restricting the Fe-N motion via $\pi-\pi$ stacking with another pyridine, was also operational for increasing the ESL in a heteroleptic Fe(II) complex, designed by the Wärnmark group, with one bipyridine and two bis(triazole-phenyl) ligands, ${ }^{14,33}$ and claimed to be important for a recently designed panchromatic Fe complex. ${ }^{12}$ It is unclear how far one can get, in terms of ESL, with an increasingly hindered Fe-N elongation, but this can be a future direction of improvement.

From a purely computational and spectroscopic point of view, comparing homoleptic tri- and bidentate complexes with $4^{27,28,30}$ and respectively $3^{31,32}$ carbene bonds, it is remarkable to observe that the former are characterized by an excited state absorption with one dominant band and single 
triplet state, while the latter display a parallel population of two excited triplet states. Since this seems to be a general observation for the numerous complexes with tri- and bidentate ligands investigated, further work is needed to understand the origin of this effect and how these transitions reflect the dynamically changing ${ }^{3} \mathrm{MC}$ or ${ }^{3} \mathrm{MLCT}$ character of the excited states. Note that the heteroleptic complex with tridentate ligands and three Fe-carbene bonds studied by Zimmer et al., ${ }^{24}$ displays yet another scheme, namely a sequential excited state relaxation:

${ }^{3} M L C T \rightarrow M C \rightarrow S_{0}$. However, for a detailed and accurate study of the excited state relaxation scenario (parallel, sequential, with or without branching), transient absorption spectroscopy is not enough discriminating as we demonstrated with the validity of both Schemes 2 and 3. Hence, additional ultrafast spectroscopic and structural methods, ${ }^{14,53}$ in combination with dynamic simulations, are expected to play an increasing role in the near future.

\section{ASSOCIATED CONTENT}

Electronic Supplementary Information (ESI) available: [NMR, spectroscopic and electrochemical data for complexes, and additional computational and photophysical details]. See DOI: 10xxxxx

\section{Conflicts of interest}

There are no conflicts to declare.

\section{Author Contributions}

The manuscript was written through contributions of all authors. All authors have given approval to the final version of the manuscript.

\section{ACKNOWLEDGMENT}


The project is funded by the French Agence Nationale de Recherche (ANR-16-CE07-0013-02).

The L2CM laboratory is grateful to F. Lachaud and F. Dupire for mass spectrometry, Ulises Carrillo for some sample preparation, Véronique Vaillant and Sandrine Rupp (LCPA2MC) for NMR experiments, IPCMS to O. Crégut for expert lab assistance and B. Marekha for help with the target analysis. The Strasbourg group acknowledges financial support through the Labex NIE. A.F.-M. acknowledges the Generalitat Valenciana and the European Social Fund (APOSTD/2019/149) and the Ministerio de Ciencia e Innovación (project CTQ2017-87054-C22-P) for the financial support. All calculations have been done using the local computing resources of the LPCT laboratory.

\section{REFERENCES}

(1) Scholl, M.; Ding, S.; Lee, C. W.; Grubbs, R. H. Synthesis and Activity of a New Generation of Ruthenium-Based Olefin Metathesis Catalysts Coordinated with 1,3-Dimesityl-4,5Dihydroimidazol-2-Ylidene Ligands ${ }^{\S}$. Org. Lett. 1999, 1, 953-956.

(2) Kantchev, E. A. B.; O’Brien, C. J.; Organ, M. G. Palladium Complexes of N-Heterocyclic Carbenes as Catalysts for Cross-Coupling Reactions-A Synthetic Chemist's Perspective. Angew. Chem. Int. Ed. 2007, 46, 2768-2813.

(3) Hopkinson, M. N.; Richter, C.; Schedler, M.; Glorius, F. An Overview of N-Heterocyclic Carbenes. Nature 2014, 510, 485-496.

(4) Fortman, G. C.; Nolan, S. P. N-Heterocyclic Carbene (NHC) Ligands and Palladium in Homogeneous Cross-Coupling Catalysis: A Perfect Union. Chem. Soc. Rev. 2011, 40 (10), 5151-5169.

(5) Díez-González, S.; Marion, N.; Nolan, S. P. N-Heterocyclic Carbenes in Late Transition Metal Catalysis. Chem. Rev. 2009, 109, 3612-3676.

(6) Crabtree, R. H. Organometallic Alkane CH Activation. J. Organomet. Chem. 2004, 689, 4083-4091.

(7) Ponseca, C. S.; Chábera, P.; Uhlig, J.; Persson, P.; Sundström, V. Ultrafast Electron Dynamics in Solar Energy Conversion. Chem. Rev. 2017, 117, 10940-11024.

(8) Duchanois, T.; Liu, L.; Pastore, M.; Monari, A.; Cebrián, C.; Trolez, Y.; Darari, M.; Magra, K.; Francés-Monerris, A.; Domenichini, E.; Beley, M.; Assfeld, X.; Haacke, S.; Gros, P. NHC-Based Iron Sensitizers for DSSCs. Inorganics 2018, 6, 63.

(9) Lindh, L.; Chábera, P.; Rosemann, N. W.; Uhlig, J.; Wärnmark, K.; Yartsev, A.; Sundström, V.; Persson, P. Photophysics and Photochemistry of Iron Carbene Complexes for Solar Energy Conversion and Photocatalysis. Catalysts 2020, 10, 315. 
(10) Wenger, O. S. Photoactive Complexes with Earth-Abundant Metals. J. Am. Chem. Soc. 2018, 140, 13522-13533.

(11) McCusker, J. K. Electronic Structure in the Transition Metal Block and Its Implications for Light Harvesting. Science 2019, 363, 484-488.

(12) Braun, J. D.; Lozada, I. B.; Kolodziej, C.; Burda, C.; Newman, K. M. E.; van Lierop, J.; Davis, R. L.; Herbert, D. E. Iron(Ii) Coordination Complexes with Panchromatic Absorption and Nanosecond Charge-Transfer Excited State Lifetimes. Nat. Chem. 2019, 11, 11441150 .

(13) Marchini, E.; Darari, M.; Lazzarin, L.; Boaretto, R.; Argazzi, R.; Bignozzi, C. A.; Gros, P. C.; Caramori, S. Recombination and Regeneration Dynamics in FeNHC (II)-Sensitized Solar Cells. Chem. Commun. 2020, 56, 543-546.

(14) Tatsuno, H.; Kjær, K. S.; Kunnus, K.; Harlang, T. C. B.; Timm, C.; Guo, M.; Chàbera, P.; Fredin, L. A.; Hartsock, R. W.; Reinhard, M. E. et al. Hot Branching Dynamics in a LightHarvesting Iron Carbene Complex Revealed by Ultrafast X-ray Emission Spectroscopy. Angew. Chem. Int. Ed. 2020, 59, 364-372.

(15) Clark, C. D.; Hoffman, M. Z.; Paul Rillema, D.; Mulazzani, Q. G. Photophysics of Ruthenium(II) Complexes with 2-(2'-Pyridyl) Pyrimidine and 2,2'-Bipyridine Ligands in Fluid Solution. J. Photochem. Photobiol. Chem. 1997, 110, 285-290.

(16) Consani, C.; Prémont-Schwarz, M.; ElNahhas, A.; Bressler, C.; van Mourik, F.; Cannizzo, A.; Chergui, M. Vibrational Coherences and Relaxation in the High-Spin State of Aqueous $\left[\mathrm{Fe}^{\mathrm{II}} \text { (Bpy) }{ }_{3}\right]^{2+}$. Angew. Chem. Int. Ed. 2009, 48, 7184-7187.

(17) Cannizzo, A.; van Mourik, F.; Gawelda, W.; Zgrablic, G.; Bressler, C.; Chergui, M. Broadband Femtosecond Fluorescence Spectroscopy of [Ru(Bpy)3]2+. Angew. Chem. Int. Ed. 2006, 45, 3174-3176.

(18) McCusker, J. K.; Walda, K. N.; Dunn, R. C.; Simon, J. D.; Magde, D.; Hendrickson, D. N. Subpicosecond 1MLCT .Fwdarw. 5T2 Intersystem Crossing of Low-Spin Polypyridyl Ferrous Complexes. J. Am. Chem. Soc. 1993, 115, 298-307.

(19) Monat, J. E.; McCusker, J. K. Femtosecond Excited-State Dynamics of an Iron(II) Polypyridyl Solar Cell Sensitizer Model. J. Am. Chem. Soc. 2000, 122, 4092-4097.

(20) Liu, Y.; Persson, P.; Sundström, V.; Wärnmark, K. Fe $N$-Heterocyclic Carbene Complexes as Promising Photosensitizers. Acc. Chem. Res. 2016, 49, 1477-1485.

(21) Kaufhold, S.; Wärnmark, K. Design and Synthesis of Photoactive Iron N-Heterocyclic Carbene Complexes. Catalysts 2020, 10, 132.

(22) Chábera, P.; Kjaer, K. S.; Prakash, O.; Honarfar, A.; Liu, Y.; Fredin, L. A.; Harlang, T. C. B.; Lidin, S.; Uhlig, J.; Sundström, V. et al. Fe ${ }^{\text {II }}$ Hexa $N$-Heterocyclic Carbene Complex with a 528 Ps Metal-to-Ligand Charge-Transfer Excited-State Lifetime. J. Phys. Chem. Lett. 2018, 9, 459-463.

(23) Francés-Monerris, A.; Gros, P. C.; Pastore, M.; Assfeld, X.; Monari, A. Photophysical Properties of Bichromophoric Fe(II) Complexes Bearing an Aromatic Electron Acceptor. Theor. Chem. Acc. 2019, 138, 86.

(24) Zimmer, P.; Burkhardt, L.; Friedrich, A.; Steube, J.; Neuba, A.; Schepper, R.; Müller, P.; Flörke, U.; Huber, M.; Lochbrunner, S.; Bauer, M. The Connection between NHC Ligand Count and Photophysical Properties in Fe(II) Photosensitizers: An Experimental Study. Inorg. Chem. 2018, 57, 360-373. 
(25) Steube, J.; Burkhardt, L.; Päpcke, A.; Moll, J.; Zimmer, P.; Schoch, R.; Wölper, C.; Heinze, K.; Lochbrunner, S.; Bauer, M. Excited-State Kinetics of an Air-Stable Cyclometalated Iron(II) Complex. Chem. - Eur. J. 2019, 25, 11826-11830.

(26) Liu, Y.; Harlang, T.; Canton, S. E.; Chábera, P.; Suárez-Alcántara, K.; Fleckhaus, A.; Vithanage, D. A.; Göransson, E.; Corani, A.; Lomoth, R. et al. Towards Longer-Lived Metal-to-Ligand Charge Transfer States of Iron(Ii) Complexes: An N-Heterocyclic Carbene Approach. Chem. Commun. 2013, 49, 6412-6414.

(27) Duchanois, T.; Etienne, T.; Cebrián, C.; Liu, L.; Monari, A.; Beley, M.; Assfeld, X.; Haacke, S.; Gros, P. C. An Iron-Based Photosensitizer with Extended Excited-State Lifetime: Photophysical and Photovoltaic Properties: An Iron-Based Photosensitizer with Extended Excited-State Lifetime. Eur. J. Inorg. Chem. 2015, 2015, 2469-2477.

(28) Liu, L.; Duchanois, T.; Etienne, T.; Monari, A.; Beley, M.; Assfeld, X.; Haacke, S.; Gros, P. C. A New Record Excited State ${ }^{3}$ MLCT Lifetime for Metalorganic Iron( II ) Complexes. Phys Chem Chem Phys 2016, 18, 12550-12556.

(29) Pastore, M.; Duchanois, T.; Liu, L.; Monari, A.; Assfeld, X.; Haacke, S.; Gros, P. C. Interfacial Charge Separation and Photovoltaic Efficiency in Fe( II )-Carbene Sensitized Solar Cells. Phys Chem Chem Phys 2016, 18, 28069-28081.

(30) Darari, M.; Domenichini, E.; Francés-Monerris, A.; Cebrián, C.; Magra, K.; Beley, M.; Pastore, M.; Monari, A.; Assfeld, X.; Haacke, S. et al. Iron( II ) Complexes with DiazinylNHC Ligands: Impact of $\pi$-Deficiency of the Azine Core on Photophysical Properties. Dalton Trans. 2019, 48 (29), 10915-10926.

(31) Francés-Monerris, A.; Magra, K.; Darari, M.; Cebrián, C.; Beley, M.; Domenichini, E.; Haacke, S.; Pastore, M.; Assfeld, X.; Gros, P. C.; Monari, A. Synthesis and Computational Study of a Pyridylcarbene Fe(II) Complex: Unexpected Effects of $\mathrm{Fac} / \mathrm{Mer}$ Isomerism in Metal-to-Ligand Triplet Potential Energy Surfaces. Inorg. Chem. 2018, 57, 10431-10441.

(32) Magra, K.; Domenichini, E.; Francés-Monerris, A.; Cebrián, C.; Beley, M.; Darari, M.; Pastore, M.; Monari, A.; Assfeld, X.; Haacke, S. et al. Impact of the Fac / Mer Isomerism on the Excited-State Dynamics of Pyridyl-Carbene Fe(II) Complexes. Inorg. Chem. 2019, 58, 5069-5081.

(33) Kjær, K. S.; Kaul, N.; Prakash, O.; Chábera, P.; Rosemann, N. W.; Honarfar, A.; Gordivska, O.; Fredin, L. A.; Bergquist, K.-E.; Häggström, L. et al. Luminescence and Reactivity of a Charge-Transfer Excited Iron Complex with Nanosecond Lifetime. Science 2019, 363, 249253.

(34) Francés-Monerris, A.; Gros, P. C.; Assfeld, X.; Monari, A.; Pastore, M. Toward Luminescent Iron Complexes: Unravelling the Photophysics by Computing Potential Energy Surfaces. ChemPhotoChem 2019, 3, 666-683.

(35) Stanton, C. J.; Vandezande, J. E.; Majetich, G. F.; Schaefer, H. F.; Agarwal, J. Mn-NHC Electrocatalysts: Increasing $\pi$ Acidity Lowers the Reduction Potential and Increases the Turnover Frequency for $\mathrm{CO}_{2}$ Reduction. Inorg. Chem. 2016, 55, 9509-9512.

(36) Samanta, T.; Kumar Rana, B.; Roymahapatra, G.; Giri, S.; Mitra, P.; Pallepogu, R.; Kumar Chattaraj, P.; Dinda, J. Synthesis, Structure and Theoretical Studies of Hg(II)-NH Carbene Complex of Annulated Ligand Pyridinyl[1,2-a]\{2-Pyridylimidazol\}-3-Ylidene Hexaflurophosphate. Inorganica Chim. Acta 2011, 375, 271-279.

(37) Frisch, M. J.; Trucks, G. W.; Schlegel, H. B.; Scuseria, G. E.; Robb, M. A.; Cheeseman, J. R.; Scalmani, G.; Barone, V.; Mennucci, B.; Petersson, G. A. et al. Gaussian09. Revis. D01 2010, Gaussian Inc., Wallingford CT. 
(38) Hirata, S.; Head-Gordon, M. Time-Dependent Density Functional Theory within the Tamm-Dancoff Approximation. Chem. Phys. Lett. 1999, 314, 291-299.

(39) Boese, A. D.; Handy, N. C. A New Parametrization of Exchange-Correlation Generalized Gradient Approximation Functionals. J. Chem. Phys. 2001, 114, 5497-5503.

(40) Duchanois, T.; Etienne, T.; Beley, M.; Assfeld, X.; Perpète, E. A.; Monari, A.; Gros, P. C. Heteroleptic Pyridyl-Carbene Iron Complexes with Tuneable Electronic Properties. Eur. J. Inorg. Chem. 2014, 2014, 3747-3753.

(41) Martin, R. L. Natural Transition Orbitals. J. Chem. Phys. 2003, 118, 4775-4777.

(42) Etienne, T.; Assfeld, X.; Monari, A. Toward a Quantitative Assessment of Electronic Transitions' Charge-Transfer Character. J. Chem. Theory Comput. 2014, 10, 3896-3905.

(43) Etienne, T.; Assfeld, X.; Monari, A. New Insight into the Topology of Excited States through Detachment/Attachment Density Matrices-Based Centroids of Charge. J. Chem. Theory Comput. 2014, 10, 3906-3914.

(44) Roland, T.; Léonard, J.; Hernandez Ramirez, G.; Méry, S.; Yurchenko, O.; Ludwigs, S.; Haacke, S. Sub-100 Fs Charge Transfer in a Novel Donor-Acceptor-Donor Triad Organized in a Smectic Film. Phys Chem Chem Phys 2012, 14, 273-279.

(45) Hutt, J. T.; Aron, Z. D. Efficient, Single-Step Access to Imidazo[1,5- $a$ ]Pyridine $N$ Heterocyclic Carbene Precursors. Org. Lett. 2011, 13, 5256-5259.

(46) Huynh, H. V. Electronic Properties of N-Heterocyclic Carbenes and Their Experimental Determination. Chem. Rev. 2018, 118, 9457-9492.

(47) Koto, Y.; Shibahara, F.; Murai, T. Imidazo[1,5-a]Pyridin-3-Ylidenes as $\pi$-Accepting Carbene Ligands: Substituent Effects on Properties of N-Heterocyclic Carbenes. Org. Biomol. Chem. 2017, 15, 1810-1820.

(48) Slavov, C.; Hartmann, H.; Wachtveitl, J. Implementation and Evaluation of Data Analysis Strategies for Time-Resolved Optical Spectroscopy. Anal. Chem. 2015, 87, 2328-2336.

(49) Gueye, M.; Manathunga, M.; Agathangelou, D.; Orozco, Y.; Paolino, M.; Fusi, S.; Haacke, S.; Olivucci, M.; Léonard, J. Engineering the Vibrational Coherence of Vision into a Synthetic Molecular Device. Nat. Commun. 2018, 9, 313.

(50) Cheminal, A.; Léonard, J.; Kim, S.-Y.; Jung, K.-H.; Kandori, H.; Haacke, S. 100 Fs PhotoIsomerization with Vibrational Coherences but Low Quantum Yield in Anabaena Sensory Rhodopsin. Phys. Chem. Chem. Phys. 2015, 17, 25429-25439.

(51) Britz, A.; Gawelda, W.; Assefa, T. A.; Jamula, L. L.; Yarranton, J. T.; Galler, A.; Khakhulin, D.; Diez, M.; Harder, M.; Doumy, G. et al. Using Ultrafast X-Ray Spectroscopy To Address Questions in Ligand-Field Theory: The Excited State Spin and Structure of [Fe(Dcpp) 2 ] ${ }^{2+}$. Inorg. Chem. 2019, 58, 9341-9350.

(52) Paulus, B. C.; Adelman, S. L.; Jamula, L. L.; McCusker, J. K. Leveraging Excited-State Coherence for Synthetic Control of Ultrafast Dynamics. Nature 2020, 582, 214-218.

(53) Kjær, K. S.; Zhang, W.; Alonso-Mori, R.; Bergmann, U.; Chollet, M.; Hadt, R. G.; Hartsock, R. W.; Harlang, T.; Kroll, T.; Kubiček, K. et al. Ligand Manipulation of Charge Transfer Excited State Relaxation and Spin Crossover in [Fe(2,2'-Bipyridine) 2 (CN) 2 ]. Struct. Dyn. 2017, 4, 044030. 